\title{
Composite material for thermochemical energy storage using $\mathrm{CaO} / \mathrm{Ca}(\mathrm{OH})_{2}$
}

\author{
Yolanda A. Criado*, Mónica Alonso, J. Carlos Abanades \\ Instituto Nacional del Carbón, CSIC-INCAR, C/ Francisco Pintado Fe, 26, 33011, \\ Oviedo. Spain. \\ * Corresponding Author: Tel: +34 985119090; Fax: +34 985297662; e-mail: \\ yolanda.ac@incar.csic.es
}

\begin{abstract}
This work describes a material that has improved mechanical and reactivity properties for use in thermochemical energy storage systems based on $\mathrm{CaO} / \mathrm{Ca}(\mathrm{OH})_{2}$ reversible reactions. The composite material uses sodium silicate as a binder of active $\mathrm{CaO}$ particles. The observed mechanical stability of the material is due to the formation of hard $\mathrm{Ca}$ silicates resulting from the reaction of the binder with the exterior of the $\mathrm{CaO}$ particles. A screening of the main synthesis variables affecting the composite was carried out, including $\mathrm{Ca}$ precursors of different particle size, a range of molar $\mathrm{Ca} / \mathrm{Si}$ ratios as well as the curing and calcination conditions. The most suitable material (containing $\mathrm{CaCO}_{3}$ with a particle size of $36-63 \mu \mathrm{m}$ as $\mathrm{Ca}$-precursor, a molar $\mathrm{Ca} / \mathrm{Si}$ ratio of 4.8-6.2 and calcined in air at $850^{\circ} \mathrm{C}$ ) was tested over many hydration/dehydration cycles (up to 500) in a thermogravimetric apparatus. The material sustained high molar hydration conversions (between 0.6-0.7) and crushing strength values $>2 \mathrm{~N}$ after 200 cycles when dehydrated in pure steam.
\end{abstract}




\section{Introduction}

Concentrating solar power (CSP) has an installed capacity worldwide of $3.4 \mathrm{GW}$ and is expected to grow at a fast rate in scenarios of high deployment of renewable energies ${ }^{1}$. CSP plants experience highly predictable variations in incoming energy flow, that do not necessarily match demand. The storage of excess thermal energy for short periods of time (hours) allows a high level of dispatchability of electricity from the CSP plants. The main thermal energy storage technologies are sensible, latent, sorption and reversible reaction heat storage $\mathrm{e}^{2-5}$. The last two technologies (known as thermochemical energy storage) have been the least investigated until now. Yet potentially they can yield higher energy storage densities compared to sensible or latent heat storage systems $^{6-9}$. In particular, we are interested in the use of the calcium oxide hydration/dehydration reaction, proposed by Ervin et al. in the late 70 ' $\mathrm{s}^{10-13}$ as the basis of some thermochemical energy storage systems ${ }^{10-21}$ :

$\mathrm{CaO}_{(\mathrm{s})}+\mathrm{H}_{2} \mathrm{O}_{(\mathrm{g})} \leftrightarrow \mathrm{Ca}(\mathrm{OH})_{2} \quad \Delta \mathrm{H}_{298 \mathrm{~K}}=-109 \mathrm{~kJ} / \mathrm{mol}$

This system is based on two steps: during the hydration of $\mathrm{CaO}$ in the presence of steam (discharge step), useful thermal heat is released at temperatures over $450^{\circ} \mathrm{C}$. During the charge step, the stored $\mathrm{Ca}(\mathrm{OH})_{2}$ is dehydrated using in-coming heat from the solar field (or other heat source) in the presence of a gas that purges the steam generated out of the reactor system ${ }^{10,21}$. The main advantages of this reversible reaction couple are its high reversibility and fast reaction rates ${ }^{22}$, high reaction enthalpy $\left(\Delta \mathrm{H}_{298 \mathrm{~K}}=-109\right.$ $\mathrm{kJ} / \mathrm{mol}$ ), which allows large energy storage densities, and appropriate charge and discharge temperatures $\left(400-550^{\circ} \mathrm{C}\right)$ at atmospheric pressure for an efficient heat integration with standard steam cycles. 
The most recent works on this energy storage technology have focused on two different reactor designs for carrying out the hydration/dehydration reactions: fixed beds $^{20,23-26}$ and circulating/bubbling fluidized beds ${ }^{11,21,27}$. One of the main drawbacks of fixed beds is their need of a large heat transfer network in order to extract/supply the large amount of thermal power generated/required during the hydration/dehydration reactions on a large scale. In addition, the high pressure drop of the flowing gases in the system (the reacting steam or the purge gases) can pose a problem in highly packed systems, especially if the materials swell or break up into finer particles.

In principle, fluidized bed reactor systems are a suitable option for the $\mathrm{CaO} / \mathrm{Ca}(\mathrm{OH})_{2}$ hydration/dehydration ${ }^{21}$. These systems are able to operate in continuous mode, the necessary heat transfer area is reduced (thanks to the high heat transfer coefficients within the fluidized bed), and the reactor for the hydration and dehydration steps can be decoupled from the solid storage silos. Furthermore, operations such as the solids circulation between reactors, the capture of fine solids generated by attrition, and any other solids handling operations between the storage silos can draw on the experience of similar fluidized beds that are used in the chemical or energy industry. However, prior experience of these systems has also revealed the tendency of lime particles obtained from the calcination of natural limestone to attrite ${ }^{28,29}$. Although attrition is a complex phenomenon, $\mathrm{CaO}$ particles are known to be substantially weaker than their parent $\mathrm{CaCO}_{3}$ particles $(\mathrm{CaO}$ crushing strengths are usually between $1 / 2$ to $1 / 4$ of their limestone counterparts ${ }^{30-32}$ ).

Despite the theoretical benefits of the $\mathrm{CaO} / \mathrm{Ca}(\mathrm{OH})_{2}$ system, only a few works have been published on the chemical and mechanical properties of the $\mathrm{CaO} / \mathrm{Ca}(\mathrm{OH})_{2}$ materials used for thermochemical energy storage applications ${ }^{13}, 18,22,33-36$. The ability of the particles or pellets to withstand fast reaction rates and to retain their mechanical 
integrity after many hydration/dehydration cycles is a prerequisite for process viability. The reaction kinetics under reasonable conditions for thermochemical energy storage have only recently been investigated ${ }^{18,22,33,34}$. Fast intrinsic reaction rates for the hydration and dehydration of $\mathrm{CaO} / \mathrm{Ca}(\mathrm{OH})_{2}$ at temperatures between $400-560^{\circ} \mathrm{C}$ and partial steam pressures ranging from pure steam to pure air at atmospheric pressure have been confirmed $^{22}$. At favorable operation conditions, complete hydration and dehydration (in pure steam at $450^{\circ} \mathrm{C}$ and $550^{\circ} \mathrm{C}$ respectively) can be achieved in less than 60 s and with a high level of chemical reversibility for particle sizes typical of fluidized bed reactors $(100-200 \mu \mathrm{m})$. However, it should be mentioned that severe particle breakage was detected in these tests. In all cases, a high degree of hydration/dehydration was observed to be counterproductive and the mechanical resistance of the $\mathrm{CaO}$ particles diminished as the hydration/dehydration conversion increased. Particle disintegration after just 5 hydration/dehydration cycles was observed in many conditions. Other authors investigating the mechanical stability of the material

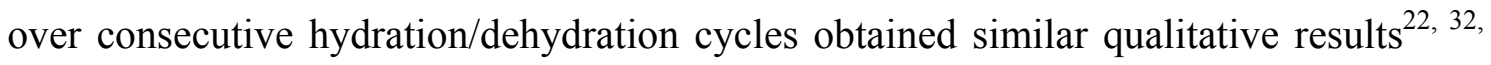
35, 37, 38 . In short, the progressive breaking and swelling mechanism of natural calcined limestone during intense hydration/dehydration reactions makes natural $\mathrm{CaO}$ materials unsuitable for practical applications in fluidized bed reactors. A similar conclusion could be drawn regarding their suitability for fixed bed applications, as the tendency to generate fines may translate into an unacceptable increase in the pressure drop of gases passing through the fixed bed reactor and/or in particle entrainment ${ }^{36}$.

The main objective of this work was to investigate ways to improve the mechanical stability of $\mathrm{CaO}$-rich pellets subjected to hydration/dehydration reactions while maintaining a high reactivity and reversibility. In the absence of sufficient literature on synthetic $\mathrm{CaO}$ materials for this purpose, we first looked at works on $\mathrm{CaO}$-based 
synthetic sorbent materials suitable for $\mathrm{CO}_{2}$ capture applications that make use of the reversible $\mathrm{CaO} / \mathrm{CaCO}_{3}$ equilibrium. As indicated in two recent reviews on the subject by Kierzkowska et al. ${ }^{39}$ and Liu et al. ${ }^{40}$, two different approaches can be adopted for the synthesis of such materials: $\mathrm{CO}_{2}$ sorbents with a certain fraction of active $\mathrm{CaO}$ supported on a porous material (calcium aluminates, $\gamma-\mathrm{Al}_{2} \mathrm{O}_{3}, \mathrm{MgO}, \mathrm{SiO}_{2}, \mathrm{CuO}$, etc. $)^{40}$ and cemented sorbents with $\mathrm{CaO}$ particles embedded in a certain amount of binder ${ }^{41}$. The main disadvantage of supported $\mathrm{CaO}$-based materials for the $\mathrm{CaO} / \mathrm{Ca}(\mathrm{OH})_{2}$ system is the very modest $\mathrm{CaO}$ content that can be achieved (typically well below $30 \% \mathrm{w}$ of $\mathrm{CaO}$ ). This makes them less suitable for thermochemical energy storage applications due to the thermal ballast effect of the inert support.

The synthesis of cemented CaO-based composite sorbents seems a more appropriate manufacturing route. A larger fraction of $\mathrm{CaO}$ can form part of the composite and the individual $\mathrm{CaO}$ particles can maintain their high activity during hydration/dehydration ${ }^{22}$. To achieve this high activity, a minimum amount of a binder needs to be used to create a matrix in which the $\mathrm{CaO} / \mathrm{Ca}(\mathrm{OH})_{2}$ particles can be embedded. Cementitious binders such as binding clays (i.e. attapulgite, sepiolite, kaolinite, bentonite) ${ }^{42}$ or silica $^{36}$, that show a good chemical stability at high temperatures $\left(800-1000^{\circ} \mathrm{C}\right)$ can be employed. Other $\mathrm{CaO}$ binders used for desulfurization applications such as Portland cement, magnesium oxysulfate cement, sodium silicates and the like, may also be used in combination with one or more cementitious clays, or separately ${ }^{42,43}$. However, many of these binders are known to swell when subjected to hydration conditions ${ }^{44}$ and other promising options ${ }^{45}$ have yet to be tested under realistic conditions for thermochemical energy storage applications at high temperature (in pure steam at $400-550^{\circ} \mathrm{C}$ ). 
One of the possible candidates for use as binder for thermochemical storage applications was mentioned in an early work by Bauerle et al. ${ }^{13}$. They tested sodium silicate, $\mathrm{Na}_{2} \mathrm{Si}_{3} \mathrm{O}_{7}$, as a binder for a $\mathrm{MgO} / \mathrm{Mg}(\mathrm{OH})_{2}$ energy storage material with positive results. Other authors also tested sodium silicate as binder for CaO-based cemented materials in various high-temperature applications, such as the removal of sulfur from hot gases ${ }^{42,43}$ or the synthesis of molds and cores for use in foundries to cast various metals ${ }^{46}$. Other applications of sodium silicate as a low-cost binder are in refractory cements, pellets and briquettes, where their high-temperature resistance (up to $1000^{\circ} \mathrm{C}$ ) and high mechanical strength when mixed with limestone materials can be used to full advantage ${ }^{47}$. This is particularly the case when a calcination step is involved during the composite synthesis, as high temperatures favor the formation of mechanically strong calcium silicates ${ }^{48}$.

The aim of this work is to screen potential composite materials between $\mathrm{CaO} / \mathrm{Ca}(\mathrm{OH})_{2}$ and $\mathrm{Na}_{2} \mathrm{Si}_{3} \mathrm{O}_{7}$ as binder and test them under realistic operation conditions for thermochemical energy storage applications. The material obtained will be the result of a compromise between the mechanical strength of the composite afforded by the binding properties of sodium silicate, and the reactivity towards hydration provided by the free $\mathrm{CaO}$ present in the composite. In this study we first screened the synthesis conditions and characterized the material in terms of chemical composition, including relevant secondary products from the reaction of $\mathrm{CaO}$ with $\mathrm{Na}_{2} \mathrm{Si}_{3} \mathrm{O}_{7}$ that may help to explain the superior mechanical properties observed in the resulting pellets. Then, the performance of the materials over hundreds of hydration/dehydration cycles was studied. Finally a mechanism has been proposed in order to interpret the observations.

\section{Experimental section}

\section{Materials}


A reagent grade Sodium silicate solution $\left(\sim 10.6 \% \mathrm{w} \mathrm{Na} \mathrm{Na}_{2} \mathrm{O}, \sim 26.5 \% \mathrm{w} \mathrm{SiO}_{2}\right.$, balance water) from Sigma-Aldrich Co LLC was used as binder. Three types of $\mathrm{CaO}$ precursor were used: (i) $\mathrm{CaCO}_{3}$ from a natural limestone (Imeco, 98.7\%w $\mathrm{CaCO}_{3}$ ), and coprecipitated calcium carbonate of reagent quality (Merck KGaA, $\mathrm{d}_{50}=14 \mu \mathrm{m}$ ), (ii) $\mathrm{CaO}$ obtained from the calcination of Imeco limestone and (iii) $\mathrm{Ca}(\mathrm{OH})_{2}$ from the total hydration of calcined Imeco limestone. For the tests in which $\mathrm{CaO}$ was used as $\mathrm{Ca}$ precursor for the composite materials, the limestone samples were calcined in an oven at $850^{\circ} \mathrm{C}$ for $1 \mathrm{~h}$. When $\mathrm{Ca}(\mathrm{OH})_{2}$ was used as precursor, the $\mathrm{CaO}$ was first hydrated using distillated liquid water before preparing the composite mix. The effect of the initial precursor particle size was studied using particle size cuts $\left(\mathrm{d}_{\mathrm{p}}\right)$ of $\mathrm{d}_{50}=14 \mu \mathrm{m}$ (coprecipitated), $<36,36-63,63-100$ and $200-400 \mu \mathrm{m}$. The composites synthesis procedure is described below.

\section{Apparatus}

To experimentally follow the hydration and dehydration reactions of the composites under controlled differential conditions, a thermogravimetric analyzer coupled to a pure steam generation line was used. The experimental set-up has been described in detail elsewhere $^{22}$. It consists of a quartz tube $\left(2.5 \times 10^{-2} \mathrm{~m}\right)$ placed in a two-zone furnace capable of working at temperatures of up to $1000^{\circ} \mathrm{C}$. The sample weight, temperatures and gas flows were continuously recorded throughout the tests. For each test a total gas flow (air or steam) of $7.3 \times 10^{-6} \mathrm{~m}^{3} / \mathrm{s}$ (at standard temperature and pressure) equivalent to $0.05 \mathrm{~m} / \mathrm{s}$ at $550^{\circ} \mathrm{C}$ was introduced to the bottom of the quartz tube. Blank tests at different gas velocities were also performed to confirm the absence of undesired diffusional effects and to correct the small weight disturbances caused by the change in the operation conditions. The steam generation line is fed from pressurized bottles. A controlled mass flow of distilled water is supplied to a pipe heated by means of a 
heating tape. A needle valve located at the end of the heated pipe introduces a deliberately high $\Delta \mathrm{P}$ to ensure a uniform and stable flow of steam due to a dampening effect. Finally, to avoid condensation, a heating cord and an air purge $\left(3.3 \times 10^{-5} \mathrm{~m}^{3} / \mathrm{s}\right)$ are placed at the top of the quartz tube.

The hydration reaction was carried out in all cases at $450^{\circ} \mathrm{C}$ in pure steam. However, two different dehydration conditions were tested $\left(500^{\circ} \mathrm{C}\right.$ in air and $550^{\circ} \mathrm{C}$ in pure steam). To evaluate the hydration/dehydration activity of the composite material, around 10-15 $\mathrm{mg}$ of calcined material (sufficiently low to avoid mass transfer limitations) was employed. For the study of the mechanical properties with the number of cycles, larger samples were used $(\sim 50 \mathrm{mg})$ at the expense of less detailed kinetic information during the initial fast hydration periods in order to be able to operate with multiple pellets and measure their crushing strength (CS) using the procedure below described. In most of these tests, the reaction time in each hydration or dehydration step was 4 min. However some cycling tests were performed for longer hydration times $\left(\mathrm{t}_{\mathrm{Hy}}\right.$ $=20 \mathrm{~min}$ and $400 \mathrm{~min}$ ) to analyze the effect of this variable.

In the case of some selected samples, up to 500 cycles were completed when the dehydration was carried out under air and up to 200 cycles when dehydration was performed under pure steam. During these tests, the thermogravimetric equipment (TG) was left over night on standby in a purge of synthetic air, for safety reasons. This led to some small errors and minor changes in the behavior of the sample during the longest testing periods (up to 8 days long). In some of these long duration experiments, a certain carbonation of the sample (due to the $\mathrm{CO}_{2}$ that diffuses from the purge air introduced into the TG head) was detected. In these cases, an occasional additional calcination of the sample was applied to restore the original value of the mass of active $\mathrm{CaO}$. 
The activity of the composite materials was evaluated using three parameters: first of all, the molar conversion of the $\mathrm{Ca}$ in the composite, which was calculated from the differences in weight as measured by the TG and from the total amount of Ca present in the pellet. The molar conversion of the $\mathrm{Ca}$ is expressed as moles of $\mathrm{H}_{2} \mathrm{O}$ absorbed per mol of $\mathrm{Ca}$ in the composite thus:

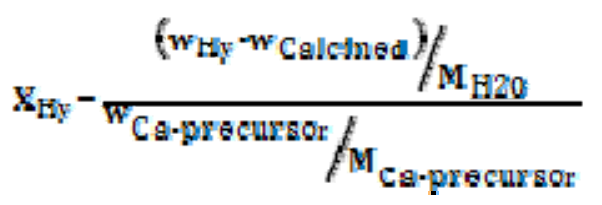

where $\mathrm{X}_{\mathrm{Hy}}$ is the hydration molar conversion of $\mathrm{Ca}, \mathrm{w}_{\mathrm{Hy}}$ and $\mathrm{w}_{\text {Calcined }}$ are the weights of the sample as measured by the TG after the hydration and calcination steps respectively, $\mathrm{w}_{\text {Ca-precursor }}$ is the weight of the Ca-precursor in the sample and $\mathrm{M}_{\mathrm{Ca} \text {-precursor }}$ is the molecular weight of the Ca-precursor.

The second parameter used to compare the results was the weight fraction of $\mathrm{H}_{2} \mathrm{O}$ absorbed per mass of calcined composite. This parameter takes a maximum theoretical value for $\mathrm{CaO}$ of 0.321 . Therefore, the $\mathrm{H}_{2} \mathrm{O}$ absorption capacity can be defined as the ratio of $\mathrm{H}_{2} \mathrm{O}$ absorbed by the composite to the maximum theoretical value for $\mathrm{CaO}$. Using these parameters, it was thus possible to discard materials and conditions that would lead to too low chemical activity (i.e. hydration molar conversions $\mathrm{X}_{\mathrm{Hy}}<0.3$ or $\mathrm{H}_{2} \mathrm{O}$ absorption capacities lower than $25 \%$ ).

In order to characterize the mechanical resistance of the materials, crushing strength (CS) measurements of the composite material pellets of around $2 \mathrm{~mm}$ were performed using a SHIMPO FGE-5X dynamometer (maximum capacity $20 \mathrm{~N}$, resolution $0.01 \mathrm{~N}$ ) supported on a SHIMPO MFGS-100L manual test stand. This measurement corresponds to the peak force (in Newtons) required to break a single round pellet. Since the pellets tested in the TG apparatus are individual particles and the CS 
measurements tend to split the pellet, the CS values given in this work for the calcined materials are the average of only three measurements. In this case the standard deviations were unusually high at around $\pm 1.0 \mathrm{~N}$. For the cycling tests consisting of hundreds of cycles, the CS measurements reported are more uncertain, as only one particle could be extracted from the TG pan after a certain number of hydration/dehydration cycles.

To identify the main chemical species present in the synthesized materials, X-Ray diffraction (XRD) tests were performed using a Bruker D8 powder diffractometer equipped with a $\mathrm{CuK} \alpha$ monochromatic X-Ray tube, a Göbel mirror in the incident beam and a parallel-slits analyzer in the diffracted beam. Diffraction data were collected by step scanning using a step size of $0.02^{\circ}$, a scan step time of $1 \mathrm{~s}$ and a scan range of $5^{\circ}$ to $60^{\circ} 2 \theta$. Morphological characterization of the material before and after cycling was performed by scanning electron microscopy (SEM) using a Quanta FEG 650 microscope equipped with an energy-dispersive X-Ray (EDX) analyzer Ametek-EDAX and an Apollo X detector.

\section{Composite samples}

The Ca-based composites were prepared by manually mixing the Ca-precursor $\left(\mathrm{CaCO}_{3}, \mathrm{Ca}(\mathrm{OH})_{2}\right.$ or $\left.\mathrm{CaO}\right)$ with the $\mathrm{Na}_{2} \mathrm{Si}_{3} \mathrm{O}_{7}$ solution at different molar ratios of $\mathrm{Ca}$ to $\mathrm{Si}\left(\mathrm{r}_{\mathrm{Ca} / \mathrm{Si}}\right.$ between 1.5 and 13.2) at ambient temperature. Cylindrical pellets of between 1$3 \mathrm{~mm}$ long and $2 \mathrm{~mm}$ diameter were manually formed using the resulting slurry of the mixture of the two components. The pellets were cured in an oven at $80^{\circ} \mathrm{C}$ for $15 \mathrm{~min}$ and then at $110^{\circ} \mathrm{C}$ for $15 \mathrm{~min}$. The temperature was finally increased to $400^{\circ} \mathrm{C}$ at a slow rate of $2^{\circ} \mathrm{C} / \mathrm{min}$ in order to avoid "bubble-like" weakening formations in the pellet, caused by water released from the $\mathrm{Na}_{2} \mathrm{Si}_{3} \mathrm{O}_{7}$ solution. The samples were typically calcined at $850^{\circ} \mathrm{C}$ in air for $10 \mathrm{~min}$. For some long-cycling tests, an initial carbonation 
step was required, as discussed later. This step was carried out in pure $\mathrm{CO}_{2}$ at temperatures between $650-750^{\circ} \mathrm{C}$ for periods ranging between $20 \mathrm{~min}$ and $1 \mathrm{~h}$. After the carbonation step, the samples were again calcined under the same conditions as during the initial calcination of the pellets.

\section{Results and discussion}

In order to establish a reference for comparing the chemical and mechanical performances of the composite materials tested in this work, initial experiments were carried out using two natural limestones subjected to calcination in air at $850^{\circ} \mathrm{C}$ as precursors of $\mathrm{CaO}$. The $\mathrm{CS}$ values of these fresh limestones ranged between 7 and $9 \mathrm{~N}$ and 3-4 $\mathrm{N}$ in the case of their calcined counterparts. After 1 or 2 hydration/dehydration cycles the CS values were lower than $2 \mathrm{~N}$ in all cases and after 20 cycles the particles were so fragile that it was impossible to collect them from the TG pan to carry out CS measurements. In line with previous discussions and references ${ }^{28-32}$, we adopted a CS threshold value of $2 \mathrm{~N}$ to disregard $\mathrm{CaO}$ composite materials with unsuitable mechanical properties. This threshold has been also used in other fluidized bed applications $^{49}$. Therefore, it could be considered very conservative for thermochemical storage systems using fixed bed reactor configurations. In contrast to their poor mechanical performance, the chemical reversibility of the fine $\mathrm{CaO}$ particles is extremely high. Experimental tests using natural calcined limestone over 300 cycles of hydration in pure steam at $450^{\circ} \mathrm{C}$ and dehydration at $500^{\circ} \mathrm{C}$ in air revealed complete conversions after just $60 \mathrm{~s}$ of hydration/dehydration. These results are in agreement with the experimental results up to 211 and 1171 cycles for other $\mathrm{CaO}$ materials and conditions reported by Ervin ${ }^{10}$ and Rosemary et al. ${ }^{12}$ respectively.

In complete contrast with the results above, a material prepared with $\mathrm{CaCO}_{3}$ as precursor of $\mathrm{CaO}$ and $\mathrm{Na}_{2} \mathrm{Si}_{3} \mathrm{O}_{7}$ as binder, yielded a composite material with a very high 
initial CS (26.0 N as indicated in Table 1) and 16.2 $\mathrm{N}$ after calcination. This is around 4 times higher than that of the original $\mathrm{CaO}$ particles of similar size, confirming the good binding properties of $\mathrm{Na}_{2} \mathrm{Si}_{3} \mathrm{O}_{7}$ after curing and after calcination, as reported by other researchers ${ }^{43,46,48}$ using different materials_ENREF 47 . In addition, the hydration conversion results reported in Table 1 support the good chemical reactivity of the pellets synthesized with $\mathrm{CaCO}_{3}$ towards hydration, as they all display fast hydration reaction rates, up to $\mathrm{X}_{\mathrm{Hy}}>0.8$ after $200 \mathrm{~s}$.

However, a drastic change in the performance of the pellets took place when $\mathrm{CaO}$ was used as Ca-precursor, as can be seen from Table 1. The preparation of these pellets required a larger fraction of binder to reach acceptable levels of mechanical strength (see their low $\mathrm{r}_{\mathrm{Ca} / \mathrm{Si}}$ in Table 1). Even with a larger fraction of binder, the pellets presented lower mechanical resistance $(\mathrm{CS}=5.9 \mathrm{~N})$. The direct reaction between $\mathrm{CaO}$ and the sodium silicate solution during the mixing of the two compounds lead to weak lumps of $\mathrm{CaO}$ rich material and a poor-quality mixture. Moreover, hydration conversion remained at a modest value (with $\mathrm{X}_{\mathrm{Hy}}$ just over 0.3 ) as $70 \%$ of the original calcium present in the sample was no longer available to form $\mathrm{Ca}(\mathrm{OH})_{2}$ during hydration. Some of the possible reactions that might have taken place between the binder and the Ca-rich particles forming the pellet will be discussed below, but no more detailed investigation was conducted on these particular materials in view of their poor chemical activity and their modest CS values. The same problems and observations applied when $\mathrm{Ca}(\mathrm{OH})_{2}$ was used as a precursor for the pellets (see third line of Table 1).

In order to facilitate comparison of the effects of the Ca-precursors, samples using $\mathrm{CaCO}_{3}$ and similar $\mathrm{r}_{\mathrm{Ca} / \mathrm{Si}}$ values to those required for $\mathrm{CaO}$ and $\mathrm{Ca}(\mathrm{OH})_{2}$ were synthesized. A similar hydration conversion to that of the other two Ca-precursors was observed (Table 1) after the composite calcination. In contrast, CS $>30 \mathrm{~N}$ was measured 
when $\mathrm{CaCO}_{3}$ was used with the same molar $\mathrm{Ca} / \mathrm{Si}$ ratio. In view of these results, all subsequent experiments were carried out using $\mathrm{CaCO}_{3}$ as $\mathrm{Ca}$-precursor.

In order to study the effect of the calcination conditions needed to generate the pellet, two calcination temperatures $\left(650\right.$ and $850^{\circ} \mathrm{C}$ in air) and two very different calcination times $(10 \mathrm{~min}$ and $16 \mathrm{~h}$ ) were applied (see Table 1 for the CS results and the main conversions measured after the hydration test). After each calcination step, a drop in CS values occurred with respect to the CS values of the material resulting from the curing process (where harder particles of $\mathrm{CaCO}_{3}$ still represent a large fraction of the pellet mass). However, the CS values of the calcined pellets were still very high (17-18 $\mathrm{N})$ when the material was calcined at high temperature $\left(850^{\circ} \mathrm{C}\right)$. In contrast, there was a remarkable drop in $\mathrm{CS}$ values (down to $\mathrm{CS}=7.5 \mathrm{~N}$ ) when the pellet was subjected to a very slow calcination process at $650^{\circ} \mathrm{C}$, lasting 16 hours. The calcination conditions also affected the hydration conversions of the calcined pellets. The samples calcined at $850^{\circ} \mathrm{C}$ presented similar conversions $\left(\mathrm{X}_{\mathrm{Hy}}=0.68\right.$ after $\left.200 \mathrm{~s}\right)$, but they increased up to $\mathrm{X}_{\mathrm{Hy}}=0.83$ when the calcination proceeded at $650^{\circ} \mathrm{C}$. This is another clear indication of the different chemical reactions that are taking place between the binder and the $\mathrm{CaO}$ particles during calcination, yielding different reaction products depending on the calcination conditions. Since the CS and reactivity properties of the pellets are clearly dependent on these solid-solid reactions, the samples were analyzed in more detail by $\mathrm{XRD}$, in order to establish the nature of the reaction products.

First, XRD analysis of the composite material was carried out before calcination, as illustrated in Figure 1a. Only the presence of $\mathrm{CaCO}_{3}$ could be ascertained in this sample, as the sodium silicate was undetectable by XRD due to its amorphous nature ${ }^{50}$. When the sample was calcined at $850^{\circ} \mathrm{C}$, the $\mathrm{CaO}$ signals appeared together with peaks clearly associated to $\mathrm{Na}_{2} \mathrm{CaSiO}_{4}$ and $\mathrm{Ca}_{2} \mathrm{SiO}_{4}$ (see Figure 1b). These silicates therefore 
must be the result of a fast solid-solid reaction between the external part of the $\mathrm{CaO}$ grains and the sodium silicate:

$\mathrm{CaO}+\mathrm{Na}_{2} \mathrm{Si}_{3} \mathrm{O}_{7} \rightarrow \mathrm{Na}_{2} \mathrm{CaSiO}_{4}+2 \mathrm{SiO}_{2}$

The formation of $\mathrm{Ca}_{2} \mathrm{SiO}_{4}$ required contact between the $\mathrm{CaO}$ and the silica formed in the previous reaction:

$2 \mathrm{CaO}+\mathrm{SiO}_{2} \rightarrow \mathrm{Ca}_{2} \mathrm{SiO}_{4}$

Previous equations (3) and (4) can be grouped as:

$5 \mathrm{CaO}+\mathrm{Na}_{2} \mathrm{Si}_{3} \mathrm{O}_{7} \rightarrow \mathrm{Na}_{2} \mathrm{CaSiO}_{4}+2 \mathrm{Ca}_{2} \mathrm{SiO}_{4}$

The reactant mobility necessary for these reactions to take place must be favored at high calcination temperatures, since the XRD analysis of the samples calcined at $650^{\circ} \mathrm{C}$ could not fully confirm the presence of $\mathrm{Ca}_{2} \mathrm{SiO}_{4}$, even after 16 hours of calcination (Figure 1c). This was also confirmed by the hydration experiments. A higher hydration conversion was obtained for the material calcined at $650^{\circ} \mathrm{C}$ compared to the material calcined at $850^{\circ} \mathrm{C}\left(\mathrm{X}_{\mathrm{Hy}}=0.83\right.$ vs $\left.\mathrm{X}_{\mathrm{Hy}}=0.68\right)$. At lower calcination temperatures, a larger fraction of free $\mathrm{CaO}$ was available to react with $\mathrm{H}_{2} \mathrm{O}$, which is consistent with the lower consumption of $\mathrm{CaO}$ in reactions (3) and (4). On the other hand, the formation of $\mathrm{Ca}_{2} \mathrm{SiO}_{4}$ and $\mathrm{Na}_{2} \mathrm{CaSiO}_{4}$ in the pellets calcined at $850^{\circ} \mathrm{C}$ must be related to the higher crushing strength values compared to those obtained at $650^{\circ} \mathrm{C}$, as the silicates formed are known to provide good mechanical properties to the Portland cement ${ }^{48}$.

Due to the importance of reactions (3) and (4) for determining the properties of the pellets, some samples were prepared so that a more detailed investigation of the nature of the reaction products could be carried out in the absence of free $\mathrm{CaO}$. For this purpose stoichiometric mixtures of $\mathrm{Ca}$ and $\mathrm{Si}\left(\mathrm{r}_{\mathrm{Ca} / \mathrm{Si}}=1.5\right)$ were prepared using very fine particles of $\mathrm{CaCO}_{3}$ (co-precipitated, $\mathrm{d}_{50}=14 \mu \mathrm{m}$ ). In this specific case, the sample was 
calcined in an oven at $850^{\circ} \mathrm{C}$ for $1 \mathrm{~h}$ to ensure that reactions (3) and (4) were completed. The full conversion of the initial calcium compounds was confirmed by the absence of $\mathrm{CaO}$ or $\mathrm{CaCO}_{3}$ peaks in the XRD plot of Figure 2a. XRD analysis showed the presence of $\mathrm{Ca}_{2} \mathrm{SiO}_{4}$ and $\mathrm{Na}_{2} \mathrm{CaSiO}_{4}$ as the main reaction products, together with other complex silicates like $\mathrm{Na}_{2} \mathrm{Ca}_{2} \mathrm{Si}_{2} \mathrm{O}_{7} / \mathrm{Na}_{2} \mathrm{Ca}_{3} \mathrm{Si}_{2} \mathrm{O}_{8}$. Other silicates with various $\mathrm{Ca}: \mathrm{Si}: \mathrm{Na}$ ratios may also play a role in the $\mathrm{CaO}-\mathrm{SiO}_{2}-\mathrm{Na}_{2} \mathrm{O}$ reaction system ${ }^{48,51}$ but could not be detected in this analysis. It is beyond the scope of this work to investigate in more detail the chemistry and crystalline structure of these silicates, as these aspects are still uncertain $^{52}$ in these temperature ranges, even though they are believed to have a considerable impact on the mechanical properties of these materials_ENREF 51 ENREF 52 . The results presented so far are sufficient to indicate that the formation of complex silicates is responsible for the superior mechanical properties of these composites. It is also clear that the drastic improvement in CS with respect to natural $\mathrm{CaO}$ materials is at the expense of the consumption of a fraction of the calcium originally loaded onto the composite, which will no longer be available for fast hydration after the formation of stable calcium silicates.

The above results highlight the need to minimize the quantity of binder (maximize the $\mathrm{r}_{\mathrm{Ca} / \mathrm{Si}}$ ratio) when manufacturing these composite materials. Reactions (3) and (4) seem to be very fast under the most adequate calcination temperatures and times (i.e. $850{ }^{\circ} \mathrm{C}$ for at least $10 \mathrm{~min}$ ) for these composite materials in light of the XRD results in Figures $1 \mathrm{~b}$ and $2 \mathrm{a}$. If it is assumed that both reactions (3) and (4) proceed until one of the reactants has been consumed, it is possible to calculate the fraction of free $\mathrm{CaO}$ left in the composite for hydration with respect to the total amount of $\mathrm{Ca}$ present in the sample $\left(f_{\mathrm{CaO}}\right)$ thus: 


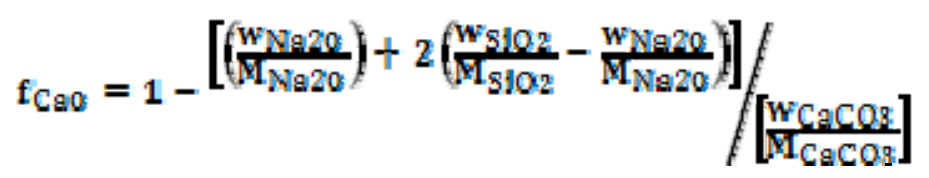

where $M_{i}$ is the molecular weight and $w_{i}$ the initial mass of each compound in the composite material. $\mathrm{w}_{\mathrm{SiO} 2}$ and $\mathrm{w}_{\mathrm{Na} 2 \mathrm{O}}$ can be estimated from the total mass of sodium silicate solution present and the composition of the sodium silicate solution. Furthermore, equation (6) can be simplified to yield equation (7), as it is inversely proportional to the molar $\mathrm{Ca} / \mathrm{Si}$ ratio in the cured composite material, $\mathrm{r}_{\mathrm{Ca} / \mathrm{Si}}$ :

$$
\mathrm{f}_{\mathrm{Cg0}}=1-\frac{1.592}{\mathrm{r}_{\mathrm{Ca} / 51}}
$$

If equation (7) is used, a stoichiometric mixture of $\mathrm{CaCO}_{3}$ and $\mathrm{Na}_{2} \mathrm{Si}_{3} \mathrm{O}_{7}\left(\mathrm{f}_{\mathrm{CaO}}=0\right)$ will have a $\mathrm{r}_{\mathrm{Ca} / \mathrm{Si}}=1.6$ (close to the experimental ratio used for the composite prepared for the XRD analysis in Figure 2a).

Equation (7) can be used to interpret the maximum hydration conversion results when using different $r_{\mathrm{Ca} / \mathrm{Si}}$ ratios. To confirm this, composites with different $r_{\mathrm{Ca} / \mathrm{Si}}$ ratios between 1.5-13.2 were prepared using the co-precipitated $\mathrm{CaCO}_{3}$ precursor to enhance the fast reactions of silicates formation. The hydration tests revealed that the hydration of the composite with a $\mathrm{r}_{\mathrm{Ca} / \mathrm{Si}}=1.5$ is very low $\left(\mathrm{X}_{\mathrm{Hy}}<0.1\right)$, which is consistent with what has been discussed above. The residual hydration detected can be explained by an incomplete conversion of $\mathrm{CaO}$ to silicates that was not detected by XRD or by a modest degree of hydration of the silicates. Other experiments conducted with $\mathrm{r}_{\mathrm{Ca} / \mathrm{Si}}$ ratios of 4.8 and 13.2, showed hydration conversions of 0.70 and 0.90 respectively, which are close to those calculated with equation (7) ( $f_{\mathrm{CaO}} 0.67$ and 0.88 respectively). The small positive deviations can again be explained by the potential ability of calcium silicates to partially hydrate during the hydration test. 
From the previous discussion, it can be inferred that there is a trade-off between the use of increasing fractions of binder to generate strong calcium silicates in the composite and the need to maximize $\mathrm{f}_{\mathrm{CaO}}$ by reducing the fraction of the binder. Since the solid-solid reactions (3) and (4) must follow a core-shell reaction pattern, it seems reasonable to assume that precursors with a larger particle size will yield different levels of conversion of $\mathrm{CaO}$ to calcium silicates to those with a finer particle size. This should have an impact on the reactivity and mechanical properties of the pellet. To confirm these effects, $\mathrm{CaCO}_{3}$ from different sources and with different particle sizes were employed: co-precipitated $\mathrm{CaCO}_{3}\left(\mathrm{~d}_{50}=14 \mu \mathrm{m}\right)$ and Imeco limestone with particle size cuts of $<36 \mu \mathrm{m}, 36-63 \mu \mathrm{m}, 63-100 \mu \mathrm{m}$ and $200-400 \mu \mathrm{m}$. The same $\mathrm{r}_{\mathrm{Ca} / \mathrm{Si}}$ ratio was used in all of these samples $\left(\mathrm{r}_{\mathrm{Ca} / \mathrm{Si}}=4.8\right)$ except in the $200-400 \mu \mathrm{m}$ sample prepared with a $\mathrm{r}_{\mathrm{Ca} / \mathrm{Si}}$ ratio of 3.2 (a lower $\mathrm{r}_{\mathrm{Ca} / \mathrm{Si}}$ was required in order to obtain mechanically stable pellets). As can be seen in Figure 3a, for Ca-precursor particle sizes lower than $100 \mu \mathrm{m}$, a hydration conversion between 0.6-0.7 was achieved within less than one minute in all cases. This result is consistent with the complete hydration of the free $\mathrm{Ca}$ fraction calculated from equation $(7)\left(f_{\mathrm{CaO}}=0.67\right)$. In contrast, for the composite prepared with a particle size of $200-400 \mu \mathrm{m}$ there is a significant gap between the experimental hydration conversion and the conversion estimated from equation (7) $\left(\mathrm{X}_{\mathrm{Hy}}=0.83\right.$ vs. $\mathrm{f}_{\mathrm{CaO}}=0.50$ ). This is consistent with the core-shell reaction pattern in which the silicate product layers become thicker for a given level of conversion as the particle size increases, so that the transport of reactants necessary to allow reactions (3) and (4) becomes slower.

From a practical point of view, the composite samples prepared with larger particles sizes, 63-100 $\mu \mathrm{m}$ and 200-400 $\mu \mathrm{m}$, present lower CS values (see Table 1), and approaching the $\mathrm{CS}$ values of the unmixed $\mathrm{CaO}$ particles. In contrast, the $\mathrm{CS}$ of the finer 
particles tends to be closer to the high values expected of the calcium silicates formed during calcination. However, if the precursor particle size is too small (co-precipitated $\mathrm{CaCO}_{3}$ ) the $\mathrm{CS}$ value also decreases as a higher fraction of $\mathrm{Na}_{2} \mathrm{Si}_{3} \mathrm{O}_{7}$ is required to manufacture strong pellets. Therefore, when activity and mechanical strength are considered together, a precursor particle size of around 36-63 $\mu \mathrm{m}$ seems to be the most suitable.

Once the most suitable particle size of the precursor was chosen, a series of tests were carried out to investigate the minimum fraction of binder needed to maintain acceptable CS values using limestone particles of 36-63 $\mu \mathrm{m}$ as $\mathrm{CaO}$ precursor. Figure $3 \mathrm{~b}$ shows the hydration conversion of the resulting samples. As expected, as the $\mathrm{r}_{\mathrm{Ca} / \mathrm{Si}}$ decreases, the hydration conversion decreases due to the fact that a larger fraction of $\mathrm{CaO}$ reacts following equations (3) and (4). When the hydration conversion predicted by $\mathrm{f}_{\mathrm{CaO}}$ (dotted line in Figure $3 b$ ) is compared with the experimental $\mathrm{X}_{\mathrm{Hy}}$, a good agreement is observed in all the samples except in the one prepared with the lower molar $\mathrm{Ca} / \mathrm{Si}$ ratio $\left(\mathrm{r}_{\mathrm{Ca} / \mathrm{Si}}=1.8\right)$. This is again an indication of an incomplete reaction between $\mathrm{CaO}$ and the $\mathrm{Na}_{2} \mathrm{Si}_{3} \mathrm{O}_{7}$ during the calcination step for the selected particle size, since the core-shell reaction pattern should impose kinetic restrictions on the progress of the reactions as the calcium silicate shell thickens around the $\mathrm{CaO}$ particles.

A comparison of the CS of the calcined composite with the highest $\mathrm{r}_{\mathrm{Ca} / \mathrm{Si}}$ ratio (1.9 $\mathrm{N})$ with the composites with a $\mathrm{r}_{\mathrm{Ca} / \mathrm{Si}}$ of between 1.8 and $6.2(\mathrm{CS}>16 \mathrm{~N})$ highlights the need for a low $\mathrm{r}_{\mathrm{Ca} / \mathrm{Si}}$ in order to ensure the material has good mechanical properties. In the light of these results, for composite material prepared using $\mathrm{CaCO}_{3}$ of $36-63 \mu \mathrm{m}$, values of $\mathrm{r}_{\mathrm{Ca} / \mathrm{Si}}$ between 4.8 and 6.2 can be considered a reasonable compromise between mechanical strength and activity. 
Once the most promising material was selected, tests with a high number of hydration/dehydration cycles were performed to observe the evolution of the $\mathrm{X}_{\mathrm{Hy}}$ and CS values over hundreds of cycles. 500 cycles of hydration in pure steam at $450^{\circ} \mathrm{C}$ and dehydration in air at $500^{\circ} \mathrm{C}$ were completed for the material prepared with $\mathrm{CaCO}_{3}$ of 36 $63 \mu \mathrm{m}$ and $\mathrm{a}_{\mathrm{Ca} / \mathrm{Si}}=4.8$. Figure $4 \mathrm{a}$ shows the hydration molar conversion achieved after 3 min vs. the number of hydration/dehydration cycles ( $\mathrm{N}$ cycle).

As can be seen, the degree of hydration conversion attained in the 500-cycle experiment is, in general, stable with cycling, and the values of $\mathrm{X}_{\mathrm{Hy}}$ are consistent with $\mathrm{f}_{\mathrm{CaO}}=0.67$. The $\mathrm{X}_{\mathrm{Hy}}>0.66$ during the first few cycles may be indicative of an incomplete conversion of $\mathrm{Na}_{2} \mathrm{Si}_{3} \mathrm{O}_{7}$ to calcium silicate for this specific experiment, a certain hydration of the silicates formed during calcination, or it may simply be a result of minor experimental errors during the 8-day long test. The plot in Figure 4a also reveals small discontinuities in the results and trends, which correspond to the points where the equipment was left on standby during the night (as mentioned in the experimental section). Despite these limitations to accuracy, the experiment confirms the high degree of reactivity stability of the material. Furthermore, a comparison of the $\mathrm{X}_{\mathrm{Hy}}$ vs. time curves for different hydration cycles (Figure $4 \mathrm{~b}$ ) shows the fast hydration rate at different number of cycles.

Concerning the evolution of the mechanical properties of the material tested in the experiment of Figure 4, the CS value measured at N=1 was $17.7 \mathrm{~N}$. One pellet extracted from the TG after 20 cycles retained a CS close to 13.6 N. However, after 500 cycles the CS was less than $2 \mathrm{~N}$, which is lower than the threshold value previously adopted to disregard materials with unsuitable mechanical properties for their practical application in fluidized beds. In order to investigate morphological changes that might explain this decay in CS over cycles, the material was subjected to SEM analysis. Figure 5 shows 
images of the cured pellet before calcination (Figure 5a) and after 500 cycles (Figure 5b). In the fresh sample, the $\mathrm{CaCO}_{3}$ particles can easily be distinguished from the mass of $\mathrm{Na}_{2} \mathrm{Si}_{3} \mathrm{O}_{7}$ embedding them. EDAX tests of the selected area (indicated in each SEM image by a small square) confirm two neat areas of different elemental composition for $\mathrm{CaCO}_{3}$ and sodium silicate. In contrast, after 500 cycle test the morphological appearance of the material is more homogeneous and the dense morphology of the cured sample surface has changed into a surface of higher roughness. The $\mathrm{CaO}$ particles cannot be easily differentiated from the silicate matrix by SEM and their particle size has been considerably reduced. Only EDAX analysis (squares) of this cycled particle still reveal areas rich in $\mathrm{CaO}$ from those with a mixture of $\mathrm{Ca}-\mathrm{Si}-\mathrm{Na}$, consistent with the core-shell reaction pattern mentioned above.

It is evident that major textural changes in the silicate matrix are taking place during cycling and that these must be responsible for the drastic decay in the CS values. An additional test with one long duration cycle (400 min in each reaction step, equivalent to the accumulated reaction times in previous cyclic tests) did not result in such drop in CS. This is an indication that the mechanical forces originated inside the pellet linked to the consecutive hydration and dehydration of the small grains of free $\mathrm{CaO}$ are the cause of the decay in $\mathrm{CS}$ due to the molar volume change associate with the hydration/dehydration reactions $\left(33.5\right.$ and $16.9 \mathrm{~cm}_{3} / \mathrm{mol} \mathrm{Ca}$ for $\mathrm{Ca}(\mathrm{OH})_{2}$ and $\mathrm{CaO}$ respectively) and the $\mathrm{Ca}(\mathrm{OH})_{2}$ anisotropic growth ${ }^{53}$.

Despite the observed decay in CS after 200 cycles, the results of Figure 4 suggest a promising route for manufacturing composite materials that can be used in thermochemical energy storage applications. To our knowledge, no previous study has succeeded in synthesizing such a stable material for these applications. In particular, 
when high concentrations of water vapor are used during hydration, as these conditions is inherent to any reactor and process design and therefore unavoidable ${ }^{21}$.

A common technique for evaluating materials for hydration/dehydration thermochemical applications is dehydration in $\operatorname{air}^{10,17,19,25,27}$. However, more realistic cycling operation conditions require the dehydration to be carried out in atmospheres with a substantial concentration of water vapor. A high fraction of water vapor will result from the dehydration of $\mathrm{Ca}(\mathrm{OH})_{2}$, and process efficiency will be favored by the use of steam as purge gas instead of $\mathrm{air}^{21}$. It is important therefore to acquire experimental information on how these materials behave when dehydration is carried out in the presence of high proportions of water vapor or even pure steam. This will require slightly higher dehydration temperatures in order to ensure fast dehydration reaction rates $^{22}$ (at atmospheric pressure, the equilibrium temperature of the $\mathrm{CaO} / \mathrm{Ca}(\mathrm{OH})_{2}$ system in pure steam is $\left.519^{\circ} \mathrm{C}\right)$. Therefore, cycling tests using the same material as in Figure 4 were carried out for hydration at $450^{\circ} \mathrm{C}$ and dehydration at $550^{\circ} \mathrm{C}$ under pure steam.

A drastic change in the performance of the material was detected in these new, more realistic, testing conditions. Figure 6 a shows the evolution of hydration conversion during the first 15 hydration/dehydration cycles of two similar materials (solid symbols). In the case of these two samples only the dehydration conditions (i.e., air to steam) were changed, and similar hydration times were used ( 3 and 4 min duration respectively). There is also a series of points (triangles, $t_{\mathrm{Hy}}=20 \mathrm{~min}$ ), where the hydration step was extended to $20 \mathrm{~min}$ for each cycle. This was intended to see whether the decay observed in the hydration capacity of the materials dehydrated under pure steam (solid circles in Figure 6a) was due to kinetic limitations during hydration or to a more fundamental deactivation mechanism. 
Some examples of the $\mathrm{X}_{\mathrm{Hy}}$ vs. time curves linked to points in Figure 6a are also plotted in Figure $6 \mathrm{~b}$. As can be seen, when the hydration lasts 20 minutes there are no significant differences in the plots of $\mathrm{X}_{\mathrm{Hy}}$ vs $\mathrm{N}$ cycle. Furthermore, the $\mathrm{f}_{\mathrm{CaO}}$ value calculated from equation (7) is consistent with this experimental measurement. Since the reactivity of free $\mathrm{CaO}$ grains in the interior of the composite is known to be very $\operatorname{high}^{22}$, these results point to increasing diffusional limitations in the silicates matrix that impede the diffusion of steam as the most likely explanation for the decay in $\mathrm{X}_{\mathrm{Hy}}$ over short hydration times. These restrictions must be linked to textural and/or chemical changes taking place in these complex materials due to the prolonged presence of water vapor at high temperatures (in particular under pure steam at $550^{\circ} \mathrm{C}$ during dehydration).

In order to further elucidate the deactivation mechanism observed in Figure 6 and in other experiments undertaken with steam as dehydration gas, XRD analyses of hydrated samples after 20 hydration/dehydration cycles were performed, for both tests in which dehydration was carried out at $500^{\circ} \mathrm{C}$ in air and in pure steam at $550^{\circ} \mathrm{C}$. The XRD results are presented in Figures $7 \mathrm{a}$ and $\mathrm{b}$ respectively. $\mathrm{CaO}$ and $\mathrm{Ca}(\mathrm{OH})_{2}$ were detected by XRD, accompanied by $\mathrm{Ca}_{2} \mathrm{SiO}_{4}$ and $\mathrm{Na}_{2} \mathrm{CaSiO}_{4}$ signals. The most significant difference between the XRD results of the calcined sample (see Figure 1b) and those obtained after 20 hydration/dehydration cycles (Figure 7) was the presence of complex silicate hydrated forms, mainly $\mathrm{Ca}_{5}\left(\mathrm{SiO}_{4}\right)_{2}(\mathrm{OH})_{2}$ (calciochondrodite or reinhardbraunsite). The presence of these hydrated silicates, allows the main reaction patterns taking place during the cycling experiments to be identified. In addition to this, the presence of free $\mathrm{CaO}$ was also detected in the sample after 20 cycles in which the dehydration step was carried out under pure steam (Figure 7b). This confirms the results of Figure 6 which show that no complete hydration of the free $\mathrm{CaO}$ was achieved. 
The interpretation of the experimental results involving dehydration in a rich atmosphere of water vapor requires information about the $\mathrm{CaO}-\mathrm{SiO}_{2}-\mathrm{H}_{2} \mathrm{O}$ reaction system. This has been extensively studied due to its relevance for building materials ${ }^{54}$. However, few studies have investigated the hydration of $\mathrm{Ca}_{2} \mathrm{SiO}_{4}$ at conditions above $200^{\circ} \mathrm{C}^{55-59}$. It is known that the formation of $\mathrm{Ca}_{5}\left(\mathrm{SiO}_{4}\right)_{2}(\mathrm{OH})_{2}$ under hydrothermal conditions at $150-600^{\circ} \mathrm{C}$, without the addition of lime or silica, follows the reaction path proposed by Speakman et al. ${ }^{55}$ :

$$
\begin{aligned}
& 9 \mathrm{Ca}_{2} \mathrm{SiO}_{4}+2 \mathrm{H}_{2} \mathrm{O} \rightarrow 2 \mathrm{Ca}_{5}\left(\mathrm{SiO}_{4}\right)_{2}(\mathrm{OH})_{2}+\mathrm{Ca}_{8}\left(\mathrm{SiO}_{4}\right)_{2}\left(\mathrm{Si}_{3} \mathrm{O}_{10}\right) \\
& 8 \mathrm{Ca}_{8}\left(\mathrm{SiO}_{4}\right)_{2}\left(\mathrm{Si}_{3} \mathrm{O}_{10}\right)+2 \mathrm{H}_{2} \mathrm{O} \rightarrow 9 \mathrm{Ca}_{6}\left(\mathrm{SiO}_{4}\right)\left(\mathrm{Si}_{3} \mathrm{O}_{10}\right)+2 \mathrm{Ca}_{5}\left(\mathrm{SiO}_{4}\right)_{2}(\mathrm{OH})_{2} \\
& 3 \mathrm{Ca}_{6}\left(\mathrm{SiO}_{4}\right)\left(\mathrm{Si}_{3} \mathrm{O}_{10}\right)+6 \mathrm{Ca}_{5}\left(\mathrm{SiO}_{4}\right)_{2}(\mathrm{OH})_{2}+2 \mathrm{H}_{2} \mathrm{O} \rightarrow 8 \mathrm{Ca}_{6}\left(\mathrm{SiO}_{4}\right)\left(\mathrm{Si}_{2} \mathrm{O}_{7}\right)(\mathrm{OH})_{2}
\end{aligned}
$$

Hydration tests of $\mathrm{Ca}_{2} \mathrm{SiO}_{4}$ at high temperatures by Yanagisawa et al ${ }^{56}$ concluded that, at temperatures higher than $400^{\circ} \mathrm{C}$, the main hydrated product observed is reinhardbraunsite (which is consistent with the results of our experimental analysis by XRD). Furthermore, in a recent work by Roßkopf et al. ${ }^{36}$ in which $\mathrm{CaO} / \mathrm{Ca}(\mathrm{OH})_{2}$ samples were mixed with nanostructured silica, $\mathrm{Ca}_{5}\left(\mathrm{SiO}_{4}\right)_{2}(\mathrm{OH})_{2}$ was also detected as the main hydrated silicate compound formed during the hydration/dehydration tests at temperatures between $400-600^{\circ} \mathrm{C}$. However, minor traces of other complex forms with various ratios of $\mathrm{Ca} / \mathrm{Si}$ such as kilchoanite, $\mathrm{Ca}_{6}\left(\mathrm{SiO}_{4}\right)\left(\mathrm{Si}_{3} \mathrm{O}_{10}\right)$, foshagite, $\mathrm{Ca}_{4}\left(\mathrm{Si}_{3} \mathrm{O}_{9}\right)(\mathrm{OH})_{2}$ or dellaite, $\mathrm{Ca}_{6}\left(\mathrm{SiO}_{4}\right)\left(\mathrm{Si}_{2} \mathrm{O}_{7}\right)(\mathrm{OH})_{2}$, may also be present at these high temperatures ${ }^{15,21}$. Furthermore, other amorphous or poorly crystalline hydrated calcium silicate forms (known as C-S-H, which is the principal binding phase in most concretes) undetectable by XRD analysis, may also form by direct hydration of $\mathrm{Ca}_{2} \mathrm{SiO}_{4}{ }^{48,54}$ :

$\mathrm{Ca}_{2} \mathrm{SiO}_{4}+\mathrm{H}_{2} \mathrm{O} \rightarrow \mathrm{Ca}_{2}\left(\mathrm{HSiO}_{4}\right)(\mathrm{OH})$ 
The transformation mechanism, the exact reaction sequence and the nature and crystalline phases of the products during the hydration/dehydration of these hydrated calcium silicates is still a controversial issue among specialists ${ }^{58,59}$ and it is beyond the scope of this work to contribute to this debate. However, we have proposed a simplified reaction mechanism (Figure 8 ) that provides a satisfactory qualitative explanation of all our XRD observations, reactivity measurements and crushing strength trends.

Figure 8 has been constructed assuming that reactions (3) and (4) are complete and follow a core-shell reaction pattern. After the first calcination, (see middle of Figure 8) a composite with a large fraction of unreacted $\mathrm{CaO}$ surrounded by micro-grains of the products of reactions (3) and (4) is obtained. The resulting matrix of micro-grains of $\mathrm{Na}_{2} \mathrm{CaSiO}_{4}$ and $\mathrm{Ca}_{2} \mathrm{SiO}_{4}$ is responsible for the improved mechanical properties of the material. This initial silicate matrix must also have a suitable porosity to allow steam to permeate and react with the free $\mathrm{CaO}$ grains to form $\mathrm{Ca}(\mathrm{OH})_{2}$ during the hydration step. As pointed out above, there must be a progressive hydration of the cementitious part (right hand side of Figure 8) towards hydrated silicates with a large molecular volume $\left(50.1 \mathrm{~cm}^{3} / \mathrm{mol} \mathrm{Ca}\right.$ has been reported ${ }^{48}$ for the amorphous material $\mathrm{Ca}_{2}\left(\mathrm{HSiO}_{4}\right)(\mathrm{OH})$, compared to 25.8 for $\left.\mathrm{Ca}_{2} \mathrm{SiO}_{4}\right)$.

According to the thermodynamic equilibrium ${ }^{55-59}$ the formation of these hydrated silicate compounds must take place in all the samples during hydration at $450^{\circ} \mathrm{C}$ in pure steam, irrespective of the dehydration conditions. However, when the dehydration step is carried out in air at $500^{\circ} \mathrm{C}$, the dehydration of some of these hydrated silicates is thermally allowed ${ }^{58,59}$. This would explain why the material in Figure 4 displays a stable reactivity up to 500 cycles. In contrast, when the dehydration is carried out under pure steam at $550^{\circ} \mathrm{C}$, the presence of hydrated silicates in the cementitious matrix increases with the number of cycles. This reduces the porosity of the silicates layer and 
causes the decay in hydration rates observed in Figure 6a (solid circles). The diffusion of steam through the resultant partially hydrated silicate matrix is therefore slower than in freshly calcined samples. However, if longer hydration times are allowed to overcome the increased resistance to the diffusion of steam, the observed decay in hydration capacity over cycling is negligible (see Figure $6 \mathrm{a}, \mathrm{t}_{\mathrm{Hy}}=20 \mathrm{~min}$ ).

In view of these results, and in order to try to maintain the activity over a high number of cycles, tests with occasional calcination steps to dehydrate the hydrated silicates were performed. However, these tests only partially succeeded in their objective. The samples resulting from these calcinations recovered part of their initial reactivity, but the hydration reaction rates observed were even lower than in the original calcined sample. To investigate more closely possible textural and/or chemical changes on the material of Figure 8, an additional carbonation reaction step was considered. This reaction is known to confer higher mechanical properties on some cements rich in $\mathrm{Ca}$ silicates by a process known as " $\mathrm{CO}_{2}$ curing" $"$. It is clear that any carbonation of the silicates present in the pellet will also lead to the carbonation of the free $\mathrm{CaO}$ particles. Therefore a calcination step after the carbonation reaction must be performed and only textural changes associated with rearrangements, at microscopic scale, of the Ca-silicate compounds can be considered when comparing the performances of calcined pellets subjected to different cycles of carbonation.

The introduction of this additional carbonation/calcination step led to a major improvement in the reactivity of the materials without causing any deterioration in their superior mechanical properties. Figure 9a shows the hydration conversion vs. the number of hydration/dehydration cycles up to 60 cycles for a small sample $(10 \mathrm{mg})$ subjected to an initial carbonation/calcination step. This small sample served to obtain accurate $X_{H y}$ vs. time curves (Figure 9b). Longer cycling tests (up to 200 cycles) were 
carried out with similar materials but using a much larger sample mass (55 mg), to be able to measure the evolution of the CS values during cycling (Figure 10). Figure 10 does not show the kinetic data for these cyclic experiments since they were affected by additional diffusion limitations in the sample pan, leading to initially lower hydration conversions $\left(\mathrm{X}_{\mathrm{Hy}} \approx 0.45\right)$ at the end of the 4 min hydration step.

As can be seen from Figure 9, the hydration reaction rate over cycling is faster and more sustained than in Figure 6. Furthermore, the hydration proceeds in two steps irrespective of the number of cycles and the maximum hydration molar conversion of around 0.67 is sustained during cycling (consistent with a value of $\mathrm{f}_{\mathrm{CaO}}=0.74$ ). During the dehydration step (Figure 9b, blank points), complete reaction is achieved in around $100 \mathrm{~s}$, which is comparable with the kinetics of natural calcined limestone $\mathrm{e}^{22}$. The need for fast reaction rates is essential for both fluidized bed and fixed bed reactor configurations. In a previous work ${ }^{21}$, we used a basic fluidized bed hydrator/dehydrator reactor model that exploits this high reactivities (comparable to that of fresh particles of $\mathrm{CaO})$ to predesign reactors with reasonable dimensions for large scale energy storage systems. Another key design parameter in these systems is the chemical energy storage density $(2080 \mathrm{~kJ} / \mathrm{kg}$ for pure $\mathrm{CaO})$ that is reduced by half for the best materials tested in this work due to the need to accommodate the silicates responsible for their superior mechanical strength.

As Figure 10 shows, the high reactivity and reversibility of the material of Figure 9 towards the hydration and dehydration is accompanied by high values of crushing strength, $\mathrm{CS}>7 \mathrm{~N}$, for all samples subjected to fewer than 100 hydration/dehydration cycles. To our knowledge, no previous material has ever been reported with such superior chemical and mechanical properties capable of resisting so many hydration/dehydration cycles of $\mathrm{CaO} / \mathrm{Ca}(\mathrm{OH})_{2}$. However, the mechanical resistance of 
the material gradually deteriorates towards a value of $\mathrm{CS}=2 \mathrm{~N}$ after 200 cycles. Therefore, it is clear that there is still scope for optimizing similar composite materials and for improvement of the results reported in Figures 9 and 10.

To facilitate future progress in the synthesis of these materials, we investigated by XRD analysis the chemical species that appear after the carbonation step. This analysis (Figure 7c) revealed the presence of the same hydrated silica compounds as in the samples without the carbonation step. However in this case, the peaks associated to $\mathrm{CaO}$ were less clear than when no carbonation step was included (see Figure 7b). Further XRD analyses were performed for the calcined samples prepared with very fine limestone $\left(\mathrm{d}_{50}=14 \mu \mathrm{m}\right)$ and a low $\mathrm{r}_{\mathrm{Ca} / \mathrm{Si}}=1.5$ after subsequent carbonations at $750^{\circ} \mathrm{C}$ and $650^{\circ} \mathrm{C}$ (Figures $2 \mathrm{~b}$ and $\mathrm{c}$, respectively). After carbonation under pure $\mathrm{CO}_{2}$, both at $750^{\circ} \mathrm{C}$ and $650^{\circ} \mathrm{C}, \mathrm{Na}_{2} \mathrm{Ca}\left(\mathrm{CO}_{3}\right)_{2}$ and $\mathrm{Na}_{2} \mathrm{Ca}_{2}\left(\mathrm{CO}_{3}\right)_{3}$ were detected, together with small peaks for $\mathrm{Ca}_{5}\left(\mathrm{SiO}_{4}\right)_{2} \mathrm{CO}_{3}$. The presence of these carbonates in these $\mathrm{XRD}$ analyses is expected since at atmospheric pressures and moderate temperatures $\left(<700^{\circ} \mathrm{C}\right)$, it is well known ${ }^{61}$ that $\mathrm{Ca}_{2} \mathrm{SiO}_{4}$ can react with $\mathrm{CO}_{2}$ to form $\mathrm{SiO}_{2}$ and $\mathrm{CaCO}_{3}$ :

$\mathrm{Ca}_{2} \mathrm{SiO}_{4}+\mathrm{CO}_{2} \leftrightarrow \mathrm{CaCO}_{3}+\mathrm{SiO}_{2}$

In addition, other crystalline carbonated calcium silicates (more stable than $\mathrm{CaCO}_{3}$ at high temperatures) may form ${ }^{62}$, such as:

$2 \mathrm{Ca}_{2} \mathrm{SiO}_{4}+\mathrm{CO}_{2}+\mathrm{CaO} \leftrightarrow \mathrm{Ca}_{5}\left(\mathrm{SiO}_{4}\right)_{2} \mathrm{CO}_{3}$

or even amorphous carbonated silicates ${ }^{63}$, as well as sodium silicate carbonates ${ }^{64}$ :

$\mathrm{Na}_{2} \mathrm{CaSiO}_{4}+2 \mathrm{CO}_{2} \leftrightarrow \mathrm{Na}_{2} \mathrm{Ca}\left(\mathrm{CO}_{3}\right)_{2}+\mathrm{SiO}_{2}$

The formation of these carbonated compounds was also corroborated by an increment in mass during the $\mathrm{TG}$ analysis at $750^{\circ} \mathrm{C}$ in $\mathrm{CO}_{2}\left(0.063 \mathrm{mg}\right.$ of $\mathrm{CO}_{2}$ per $\mathrm{mg}$ of the calcined sample, equivalent to $0.249 \mathrm{~mol} \mathrm{CO}_{2} / \mathrm{mol}$ total). At lower carbonation 
temperatures $\left(650^{\circ} \mathrm{C}\right)$ a small fraction of $\mathrm{CaCO}_{3}$ was also detected by XRD. This was formed by direct decomposition of $\mathrm{Ca}_{2} \mathrm{SiO}_{4}$ into $\mathrm{CaCO}_{3}$ and $\mathrm{SiO}_{2}$ (reaction 12) since this reaction is allowed by the thermodynamics ${ }^{65}$ and there is no other possible source of $\mathrm{CaCO}_{3}$. In these lower carbonation conditions, the increment in mass observed in the TG was significantly higher than that recorded in the test at $750^{\circ} \mathrm{C}\left(0.083 \mathrm{mg}\right.$ of $\mathrm{CO}_{2}$ per $\mathrm{mg}$ of calcined sample, equivalent to $0.329 \mathrm{~mol} \mathrm{CO}_{2} / \mathrm{mol}$ total), as might be expected from reaction (12). Additional XRD analysis of the carbonated samples at $750^{\circ} \mathrm{C}$ in pure $\mathrm{CO}_{2}$ and prepared with a higher $\mathrm{r}_{\mathrm{Ca} / \mathrm{Si}}$ of 4.8 and larger Ca-particles sizes $\left(\mathrm{CaCO}_{3} 36-63 \mu \mathrm{m}\right)$, also revealed the presence of $\mathrm{Na}_{2} \mathrm{Ca}\left(\mathrm{CO}_{3}\right)_{2}$ and $\mathrm{Ca}_{5}\left(\mathrm{SiO}_{4}\right)_{2} \mathrm{CO}_{3}$.

Other calcination/carbonation/calcination sequences (involving carbonation tests of up to 1 hour or different numbers of carbonation/calcination cycles) as well as other carbonation temperatures $\left(650-750^{\circ} \mathrm{C}\right)$ were explored. However, no relevant improvements were detected during these other tests. The only difference worthy to note was that, when the carbonation temperature was reduced to $650^{\circ} \mathrm{C}$, the material obtained yielded lower CS values $(\sim 10 \mathrm{~N})$ than when the carbonation was carried out at $750^{\circ} \mathrm{C}(\sim 18 \mathrm{~N})$. This indicates that the formation of free $\mathrm{CaCO}_{3}$ during carbonation at $650^{\circ} \mathrm{C}$ (reaction 12) is counterproductive for the mechanical properties of the material. In summary, it seems that a single, relatively short carbonation step (around 20 min in pure $\mathrm{CO}_{2}$ at $750^{\circ} \mathrm{C}$ ) is the key to obtaining a substantial improvement in material properties over hundreds of cycles of hydration/dehydration in pure steam.

The previous discussion and observations are summarized in Figure 11, which has been constructed following similar guidelines as those of Figure 8: all reactions in the cementitious matrix are assumed to follow a core-shell pattern and it is assumed that the hydrated species of calcium silicates are responsible for the decay in the kinetics of hydration reaction shown in Figure 6. As in Figure 8, after the first calcination, the 
material is characterized by grains of $\mathrm{CaO}$ embedded in a matrix of micro-grains of $\mathrm{Na}_{2} \mathrm{CaSiO}_{4}$ and $\mathrm{Ca}_{2} \mathrm{SiO}_{4}$. Under carbonation conditions, a layer of $\mathrm{Na}_{2} \mathrm{Ca}\left(\mathrm{CO}_{3}\right)_{2}$ and $\mathrm{SiO}_{2}$ forms over the $\mathrm{Na}_{2} \mathrm{CaSiO}_{4}$ micro-grains surface. The higher molar volume per mol of $\mathrm{Ca}$ of the carbonated compound formed $\left(81.1 \mathrm{vs} .62 .7 \mathrm{~cm}^{3} / \mathrm{mol} \mathrm{Ca}\right)$ will have an expansive effect on the layer of silicates. Furthermore, traces of $\mathrm{Ca}_{5}\left(\mathrm{SiO}_{4}\right)_{2} \mathrm{CO}_{3}$ may also form in the interphase $\mathrm{CaO}$-silicates layer following reaction (13). This is possible due to the presence of an excess of $\mathrm{CaO}$, and it allows the silicate matrix to expand even more. After the second calcination, the same original compounds will form due to the decomposition of the carbonates. However, the layer of silicates will have a more open structure. In these conditions, it is reasonable to assume that the more open pore structure resulting from this carbonation/calcination step will be able to accommodate more easily the growth of the outer layers of $\mathrm{Ca}_{2} \mathrm{SiO}_{4}$ micro-grains due to the formation of hydrated silicates without any rapid blockage of the porous structure. Irrespective of the nature of the reaction mechanism, the hydration conversion results in Figure 9 show that a carbonation step at high temperatures followed by a second calcination step is essential for obtaining a composite material with a high chemical activity for the hydration/dehydration cycles under pure steam.

\section{Conclusions}

The use of $\mathrm{CaO}$ as a thermochemical energy storage material in hydration/dehydration cycles is very limited because of the very poor mechanical properties of the $\mathrm{CaO}$ particles derived from the calcination of natural limestones. The use of composite materials made up of small $\mathrm{CaO}$ particles and the products of their reactions at high temperature with $\mathrm{Na}_{2} \mathrm{Si}_{3} \mathrm{O}_{7}$ offer a promising route for overcoming this fundamental limitation. Research into the most favorable conditions for manufacturing pellets reveals that $\mathrm{CaCO}_{3}$ is the most suitable precursor as it generates after calcination 
a CaO-rich pellet with an exceptionally high crushing strength $(>26 \mathrm{~N})$. XRD analyses reveal that the superior mechanical properties of the composites with respect to the parent $\mathrm{CaO}$ materials is a result of the formation of a cementitious matrix of complex calcium silicates (i.e. $\mathrm{Na}_{2} \mathrm{CaSiO}_{4}$ and $\mathrm{Ca}_{2} \mathrm{SiO}_{4}$ ) via a core-shell reaction of the $\mathrm{CaO}$ precursor with the $\mathrm{Na}_{2} \mathrm{Si}_{3} \mathrm{O}_{7}$ at high calcination temperatures leading to CS values higher that $16 \mathrm{~N}$, which is around 4 times greater than that of the original $\mathrm{CaO}$. Screening of the synthesis conditions revealed that a favorable material is obtained by using $\mathrm{CaCO}_{3}$ with a particle size of $36-63 \mu \mathrm{m}$ as $\mathrm{Ca}$-precursor and molar $\mathrm{Ca} / \mathrm{Si}$ ratios of between 4.8 and 6.2. These materials were tested for up to 500 cycles of hydration under pure steam and dehydration under air or pure steam. During these long cycling tests, a sharp decay in the hydration capacity of the materials occurred when both hydration and dehydration were carried out under pure steam. This decay did not occur when dehydration was carried out in air at $500^{\circ} \mathrm{C}$. Analysis by XRD revealed the formation of hydrated silicates, which introduced a substantial new resistance to the hydration of the $\mathrm{CaO}$ particles. Subjecting the calcined pellet to an additional carbonation/calcination cycle, led to a more active composite material, due to an expansive effect in the cementitious matrix during the carbonation of the silicates. For the most promising samples, hydration molar conversions of around 0.6 were maintained over 200 cycles and with fast reaction rates. The crushing strength of the composite material along cycling was also favorable (CS $>7 \mathrm{~N}$ after 100 cycles) compared to that of natural $\mathrm{CaO}(\mathrm{CS}<2 \mathrm{~N}$ after $1-5$ cycles). However, the $\mathrm{CS}$ values decayed to $2 \mathrm{~N}$ after 200 cycles of hydration/dehydration under pure steam, leaving scope for further improvement of these materials for use in thermochemical energy storage systems.

\section{Acknowledgements}


Financial support provided by the European Commission under the $7^{\text {th }}$ Framework Program (StoRRe Project GA 282677) is acknowledged. Y.A. Criado thanks the Government of the Principality of Asturias for a Ph.D. fellowship (Severo Ochoa Program).

\section{References}

(1) REN21 Renewables 2014: Global Status Report; Renewable Energy Police Network for the 21st Century: Paris: REN21 Secretariat, 2014.

(2) IEA Technology Roadmap: Concentrating Solar Power; International Energy Agency: France, 2010.

(3) IPCC Special Report on Renewable Energy Sources and Climate Change Mitigation; Cambridge University Press: United Kingdom and New York, NY, USA, 2011.

(4) IRENA Renewable Energy Technologies: Cost Analysis Series - Concentrating Solar Power; International Renewable Energy Agency: United Arab Emirates, 2012.

(5) EASAC Concentrating Solar Power: Its Potential Contribution to a Sustainable Energy Future; 978-3-8047-2944-5; German Academy of Sciences Leopoldina: Germany, 2011.

(6) Xu, J.; Wang, R. Z.; Li, Y. A Review of Available Technologies for Seasonal Thermal Energy Storage. Sol. Energy 2014, 103, 610.

(7) Cot-Gores, J.; Castell, A.; Cabeza, L. F. Thermochemical Energy Storage and Conversion: A-State-of-the-Art Review of the Experimental Research Under Practical Conditions. Renew. Sust. Energ. Rev. 2012, 16, 5207.

(8) Kuravi, S.; Trahan, J.; Goswami, D. Y.; Rahman, M. M.; Stefanakos, E. K. Thermal Energy Storage Technologies and Systems for Concentrating Solar Power Plants. Prog. Energ. Combust. 2013, 39, 285. 
(9) Pardo, P.; Deydier, A.; Anxionnaz-Minvielle, Z.; Rougé, S.; Cabassud, M.; Cognet, P. A Review on High Temperature Thermochemical Heat Energy Storage. Renew. Sust. Energ. Rev. 2014, 32, 591.

(10) Ervin, G. Solar Heat Storage Using Chemical Reactions. J. Solid State Chem. 1977, $22,51$.

(11) Ervin, G. Method of storing and releasing thermal energy. U.S. Patent 3,973,552, 1976.

(12) Rosemary, J. K.; Bauerle, G. L.; Springer, T. H. Solar Energy Storage Using Reversible Hydration-Dehydration of CaO-Ca(OH)2. J. Energy 1979, 3, 321.

(13) Bauerle, G. L.; Chung, D.; Ervin, G.; Guon, J.; Springer, T. H. In Storage of Solar Energy by Inorganic Oxide/Hydroxides, Proceedings of Sharing the Sun: Solar technology in the seventies, Winnipeg, Canada, 1976; International Solar Energy Society of Canada: 8 .

(14) Schaube, F.; Worner, A.; Tamme, R. High Temperature Thermochemical Heat Storage for Concentrated Solar Power Using Gas-Solid Reactions. J. Sol. Energ. Eng. 2011, 133, 031006.

(15) Brown, D. R.; La Marche, J. L.; Spanner, G. E. Chemical Energy Storage System for Solar Electric Generating System (SEGS) Solar Thermal Power Plant. J. Sol. Energ. Eng. 1991, 114, 212.

(16) Wentworth, W. E.; Chen, E. Simple Thermal Decomposition Reactions for Storage of Solar Thermal Energy. Sol. Energy 1976, 18, 205. 
(17) Fujii, I.; Tsuchiya, K.; Higano, M.; Yamada, J. Studies of an Energy Storage

System by Use of the Reversible Chemical Reaction: $\mathrm{CaO}+\mathrm{H}_{2} \mathrm{O} \rightleftharpoons \mathrm{Ca}(\mathrm{OH})_{2}$. Sol.

Energy 1985, 34, 367.

(18) Matsuda, H.; Ishizu, T.; Lee, S. K.; Hasatani, M. Kinetic Study of $\mathrm{Ca}(\mathrm{OH})_{2} / \mathrm{CaO}$

Reversible Thermochemical Reaction for Thermal Energy Storage by Means of Chemical Reaction. Kagaku Kogaku Ronbun. 1985, 11, 542.

(19) Azpiazu, M. N.; Morquillas, J. M.; Vazquez, A. Heat Recovery from a Thermal Energy Storage Based on the $\mathrm{Ca}(\mathrm{OH})_{2} / \mathrm{CaO}$ Cycle. Appl. Therm. Eng. 2003, 23, 733.

(20) Kanzawa, A.; Arai, Y. Thermal Energy Storage by the Chemical Reaction Augmentation of Heat Transfer and Thermal Decomposition in the $\mathrm{CaO} / \mathrm{Ca}(\mathrm{OH})_{2}$ Powder. Sol. Energy 1981, 27, 289.

(21) Criado, Y. A.; Alonso, M.; Abanades, J. C. Conceptual Process Design of a $\mathrm{CaO} / \mathrm{Ca}(\mathrm{OH})_{2}$ Thermochemical Energy Storage System Using Fluidized Bed Reactors. Appl. Therm. Eng. 2014, 73, 1089.

(22) Criado, Y. A.; Alonso, M.; Abanades, J. C. Kinetics of the $\mathrm{CaO} / \mathrm{Ca}(\mathrm{OH})_{2}$ Hydration/Dehydration Reaction for Thermochemical Energy Storage Applications. Ind. Eng. Chem. Res. 2014, 53, 12594.

(23) Schaube, F.; Kohzer, A.; Schütz, J.; Wörner, A.; Müller-Steinhagen, H. De- and Rehydration of $\mathrm{Ca}(\mathrm{OH})_{2}$ in a Reactor with Direct Heat Transfer for Thermo-Chemical Heat Storage. Part A: Experimental Results. Chem. Eng. Res. Des. 2013, 91, 856. 
(24) Schaube, F.; Utz, I.; Wörner, A.; Müller-Steinhagen, H. De- and Rehydration of $\mathrm{Ca}(\mathrm{OH})_{2}$ in a Reactor with Direct Heat Transfer for Thermo-Chemical Heat Storage. Part B: Validation of Model. Chem. Eng. Res. Des. 2013, 91, 865.

(25) Schmidt, M.; Szczukowski, C.; Roßkopf, C.; Linder, M.; Wörner, A. Experimental Results of a $10 \mathrm{~kW}$ High Temperature Thermochemical Storage Reactor Based on Calcium Hydroxide. Appl. Therm. Eng. 2014, 62, 553.

(26) Darkwa, K. Thermochemical Energy Storage in Inorganic Oxides: an Experimental Evaluation. Appl. Therm. Eng. 1998, 18, 387.

(27) Pardo, P.; Anxionnaz-Minvielle, Z.; Rougé, S.; Cognet, P.; Cabassud, M. $\mathrm{Ca}(\mathrm{OH})_{2} / \mathrm{CaO}$ Reversible Reaction in a Fluidized Bed Reactor for Thermochemical Heat Storage. Sol. Energy 2014, 107, 605.

(28) Scala, F.; Chirone, R.; Salatino, P. 6 - Attrition phenomena relevant to fluidized bed combustion and gasification systems. In Fluidized Bed Technologies for Near-Zero Emission Combustion and Gasification, Scala, F., Ed. Woodhead Publishing: 2013; pp 254-315.

(29) Xiao, G.; Grace, J. R.; Lim, C. J. Evolution of Limestone Particle Size Distribution in an Air-Jet Attrition Apparatus. Ind. Eng. Chem. Res. 2014, 53, 15845.

(30) Wolff, E. H. P.; Gerritsen, A. W.; Verheijen, P. J. T. Attrition of an AluminateBased Synthetic Sorbent for Regenerative Sulphur Capture from Flue Gas in a Fluidised Bed. Powder Technol. 1993, 76, 47.

(31) Kazi, S. S.; Aranda, A.; Meyer, J.; Mastin, J. High Performance CaO-Based Sorbents for Pre- and Post- Combustion $\mathrm{CO}_{2}$ Capture at High Temperature. Energy Procedia 2014, 63, 2207.

(32) Martínez, I.; Grasa, G.; Murillo, R.; Arias, B.; Abanades, J. C. Evaluation of $\mathrm{CO}_{2}$ Carrying Capacity of Reactivated CaO by Hydration. Energy Fuels 2011, 25, 1294. 
(33) Schaube, F.; Koch, L.; Wörner, A.; Müller-Steinhagen, H. A Thermodynamic and Kinetic Study of the De- and Rehydration of $\mathrm{Ca}(\mathrm{OH})_{2}$ at High $\mathrm{H}_{2} \mathrm{O}$ Partial Pressures for Thermo-Chemical Heat Storage. Thermochim. Acta 2012, 538, 9.

(34) Irabien, A.; Viguri, J. R.; Ortiz, I. Thermal Dehydration of Calcium Hydroxide. 1. Kinetic Model and Parameters. Ind. Eng. Chem. Res. 1990, 29, 1599.

(35) Fujii, I.; Ishino, M.; Akiyama, S.; Murthy, M. S.; Rajanandam, K. S. Behavior of $\mathrm{Ca}(\mathrm{OH})_{2} / \mathrm{CaO}$ Pellet Under Dehydration and Hydration. Sol. Energy 1994, 53, 329.

(36) Roßkopf, C.; Afflerbach, S.; Schmidt, M.; Görtz, B.; Kowald, T.; Linder, M.; Trettin, R. Investigations of Nano Coated Calcium Hydroxide Cycled in a Thermochemical Heat Storage. Energ. Convers. Manage. 2015, 97, 94.

(37) Grasa, G.; Murillo, R.; Alonso, M.; González, B.; Rodriguez, N.; Abanades, J. C. In Steam Reactivation of CaO-Based Natural Sorbents Applied to a Carbonation/Calcination Loop for $\mathrm{CO}_{2}$ Capture, Proceedings of 4th International Conference on Clean Coal Technologies, Dresden, Germany, 18-21 May, 2009; http://www.cct2009.org/ibis/iea-cct-2009/my-event.

(38) Manovic, V.; Lu, D.; Anthony, E. J. Steam Hydration of Sorbents from a Dual Fluidized Bed $\mathrm{CO}_{2}$ Looping Cycle Reactor. Fuel 2008, 87, 3344.

(39) Kierzkowska, A. M.; Pacciani, R.; Müller, C. R. CaO-Based $\mathrm{CO}_{2}$ Sorbents: from Fundamentals to the Development of New, Highly Effective Materials. ChemSusChem 2013, 6, 1130.

(40) Liu, W.; An, H.; Qin, C.; Yin, J.; Wang, G.; Feng, B.; Xu, M. Performance Enhancement of Calcium Oxide Sorbents for Cyclic $\mathrm{CO}_{2}$ Capture-A Review. Energy Fuels 2012, 26, 2751.

(41) Manovic, V.; Anthony, E. J. Screening of Binders for Pelletization of CaO-Based Sorbents for $\mathrm{CO}_{2}$ Capture. Energy Fuels 2009, 23, 4797. 
(42) Voss, K. E. Limestone-based sorbent agglomerates for removal of sulfur compounds in hot gases and method of making. U.S. Patent 4,316,813, 1982.

(43) Summers, J. C. Stabilization of calcium oxide sulfate trapping materials. U.S. Patent 4,061,593, 1977.

(44) Lu, D. Y; Hughes, R. W; Reid, T.; Anthony, E. J. In Hydration and Pelletization of $\mathrm{CaCO}_{3}$-Derived Sorbents for In-Situ $\mathrm{CO}_{2}$ Capture, Proceedings of 20th International Conference on Fluidized Bed Combustion, Xi'an, China, May 18-21, 2009; Yue, G.; Zhang, H.; Zhao, C.; Luo, Z., Eds.; Tsinghua University Press, Beijing and SpringerVerlag Berlin Heidelberg, 2009: http://dx.doi.org/10.1007/978-3-642-02682-9 86.

(45) Hara, M.; Mochizuki, M.; Shimazu, T.; Sobukawa, H.; Fukushima, Y.; Wakasugi, T.; Yano, K.; Itahara, H.; Sawada, T.; Fujimura, T. Chemical heat storage material structure, production method therefor, and chemical heat accumulator. Eur. Pat. Appl. $11759541.3,2013$.

(46) Ailin-Pyzik, I. B.; Falcone Jr., J. S. Method for binding particulate materials. U.S. Patent 4,347,890, 1982.

(47) McDonald, M.; Hamilton, J.; Thompson, J. Recent developments in soluble silicate based binders and coatings; PQ Corporation: 2007: www.pqcorp.com.

(48) Taylor, H. F. W Cement chemistry; Thomas Telford Publishing: 1997.

(49) Rydén, M.; Moldenhauer, P.; Lindqvist, S.; Mattisson, T.; Lyngfelt, A. Measuring Attrition Resistance of Oxygen Carrier Particles for Chemical Looping Combustion with a Customized Jet Cup. Powder Technol. 2014, 256, 75.

(50) Musi , S.; Filipovi -Vincekovi , N.; Sekovani , L. Precipitation of Amorphous $\mathrm{SiO}_{2}$ Particles and Their Properties. Braz. J. Chem. Eng. 2011, $28,89$. 
(51) Teixeira, S. R.; Romero, M.; Rincón, J. M. Crystallization of $\mathrm{SiO}_{2}-\mathrm{CaO}-\mathrm{Na}_{2} \mathrm{O}$ Glass Using Sugarcane Bagasse Ash as Silica Source. J. Am. Ceram. Soc. 2010, 93, 450.

(52) Allen, A. J.; Thomas, J. J.; Jennings, H. M. Composition and Density of Nanoscale Calcium-Silicate-Hydrate in Cement. Nat. Mater. 2007, 6, 311.

(53) Serris, E.; Favergeon, L.; Pijolat, M.; Soustelle, M.; Nortier, P.; Gärtner, R. S.; Chopin, T.; Habib, Z. Study of the Hydration of CaO Powder by Gas-Solid Reaction. Cement. Concrete Res. 2011, 41, 1078.

(54) Richardson, I. G. The Calcium Silicate Hydrates. Cement. Concrete Res. 2008, 38, 137.

(55) Speakman, K.; Taylor, H. F. W.; Bennett, J. M.; Gard, J. A. Hydrothermal Reactions of $\gamma$-Dicalcium Silicate. J. Chem. Soc. A 1967, 1052.

(56) Yanagisawa, K.; Hu, X.; Onda, A.; Kajiyoshi, K. Hydration of $\beta$-Dicalcium Silicate at High Temperatures Under Hydrothermal Conditions. Cement. Concrete Res. 2006, 36, 810 .

(57) Mitsuda, T.; Asami, J.; Matsubara, Y.; Toraya, H. Hydrothermal Formation of $\gamma$ Dicalcium Silicate from Lime-Silica Mixtures Using a Rapid-Heating Method and its Reaction to Give Kilchoanite or Calciochondrodite. Cement. Concrete Res. 1985, 15, 613.

(58) Garbev, K.; Gasharova, B.; Stemmermann, P. A Modular Concept of Crystal Structure Applied to the Thermal Transformation of $\alpha-C_{2}$ SH. J. Am. Ceram. Soc. 2014, $97,2286$.

(59) Garbev, K.; Beuchle, G.; Schweike, U.; Merz, D.; Dregert, O.; Stemmermann, P. Preparation of a Novel Cementitious Material from Hydrothermally Synthesized C-S-H Phases. J. Am. Ceram. Soc. 2014, 97, 2298. 
(60) Klemm, W. A.; Berger, R. L. Accelerated Curing of Cementitious Systems by Carbon Dioxide: Part I. Portland Cement. Cement. Concrete Res. 1972, 2, 567.

(61) Goto, S.; Suenaga, K.; Kado, T.; Fukuhara, M. Calcium Silicate Carbonation Products. J. Am. Ceram. Soc. 1995, 78, 2867.

(62) Glasser, F.P. The Formation and Thermal Stability of Spurrite, $\mathrm{Ca}_{5}\left(\mathrm{SiO}_{4}\right)_{2} \mathrm{CO}_{3}$. Cement. Concrete Res. 1973, 3, 23.

(63) Maycock, J. N.; Skalny, J. Carbonation of Hydrated Calcium Silicates. Cement. Concrete Res. 1974, 4, 69.

(64) Manovic, V.; Anthony, E. J. Improvement of CaO-Based Sorbent Performances for $\mathrm{CO}_{2}$ Looping Cycles. Therm. Sci. 2009, 13, 89.

(65) Barin, I. Thermochemical data of pure substances; VCH Verlagsgesellschaft Weinheim, Germany, 1989. 


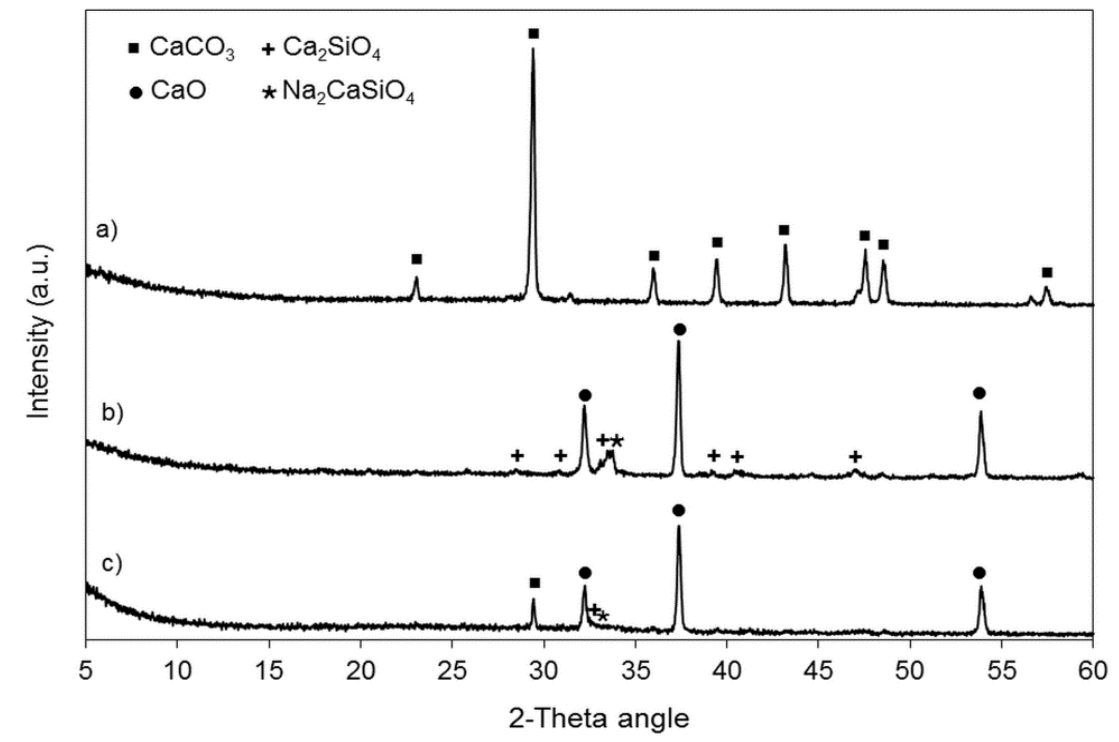

Figure 1. XRD results for a composite material prepared using $\mathrm{CaCO}_{3}$ of $36-63 \mu \mathrm{m}$ and $\mathrm{a}_{\mathrm{Ca} / \mathrm{Si}}=4.8$. a) Fresh particle (after curing), b) after calcination at $850^{\circ} \mathrm{C}$ for $10 \mathrm{~min}$ and c) after calcination at $650^{\circ} \mathrm{C}$ for $16 \mathrm{~h}$. 


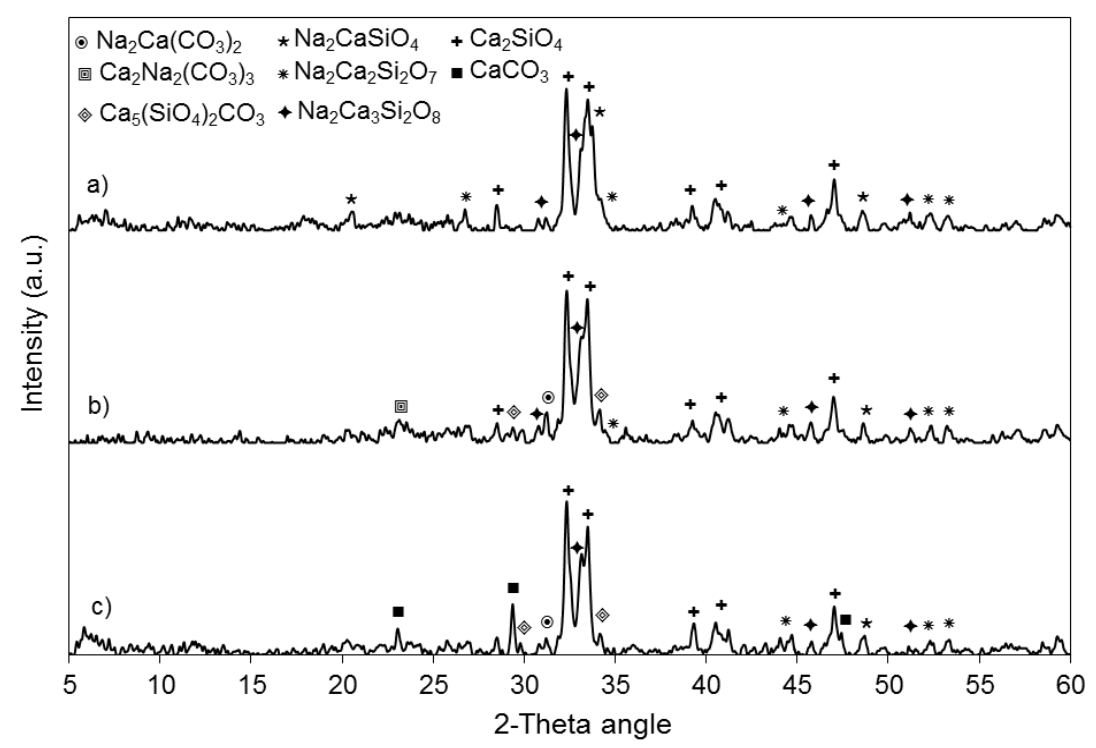

Figure 2. XRD results for a composite material prepared using co-precipitated $\mathrm{CaCO}_{3}$ $\left(\mathrm{d}_{50}=14 \mu \mathrm{m}\right)$ and $\mathrm{r}_{\mathrm{Ca} / \mathrm{Si}}=1.5$. After a) calcination at $850^{\circ} \mathrm{C}$ in an oven for $\left.1 \mathrm{~h}, \mathbf{b}\right)$ calcination at $850^{\circ} \mathrm{C}$ followed by carbonation in pure $\mathrm{CO}_{2}$ at $750^{\circ} \mathrm{C}$ and c) calcination at $850^{\circ} \mathrm{C}$ followed by carbonation in pure $\mathrm{CO}_{2}$ at $650^{\circ} \mathrm{C}$. 

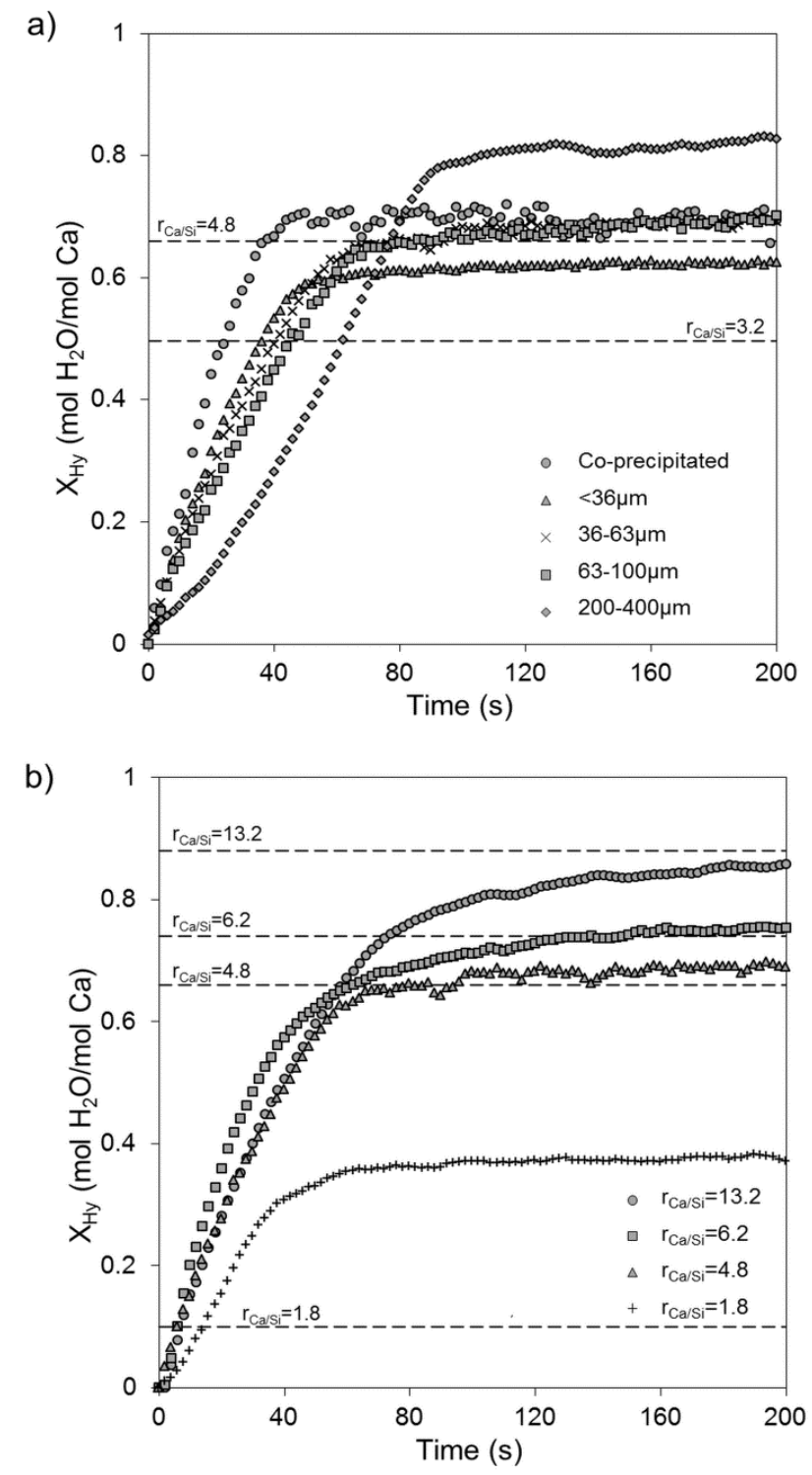

Figure 3. Hydration conversion $\left(\mathrm{X}_{\mathrm{Hy}}\right)$ as a function of time for a) five different particle sizes: co-precipitated $\mathrm{CaCO}_{3}\left(\mathrm{~d}_{50}=14 \mu \mathrm{m}\right)$ and Imeco $\mathrm{CaCO}_{3}<36,36-63,63-100$ and $200-400 \mu \mathrm{m}, \mathrm{r}_{\mathrm{Ca} / \mathrm{Si}}=4.8\left(\right.$ except for $\left.\mathrm{d}_{\mathrm{p}}=200-400 \mu \mathrm{m}, \mathrm{r}_{\mathrm{Ca} / \mathrm{Si}}=3.2\right)$ and $\mathbf{b}$ ) for four different $\mathrm{r}_{\mathrm{Ca} / \mathrm{Si}}: 13.2,6.2,4.8$ and 1.8 using Imeco $\mathrm{CaCO}_{3}$ of 36-63 $\mu \mathrm{m}$ as $\mathrm{Ca}$-precursor. Corresponding $\mathrm{f}_{\mathrm{CaO}}$ (from equation 7 ) indicated by the dotted lines. 

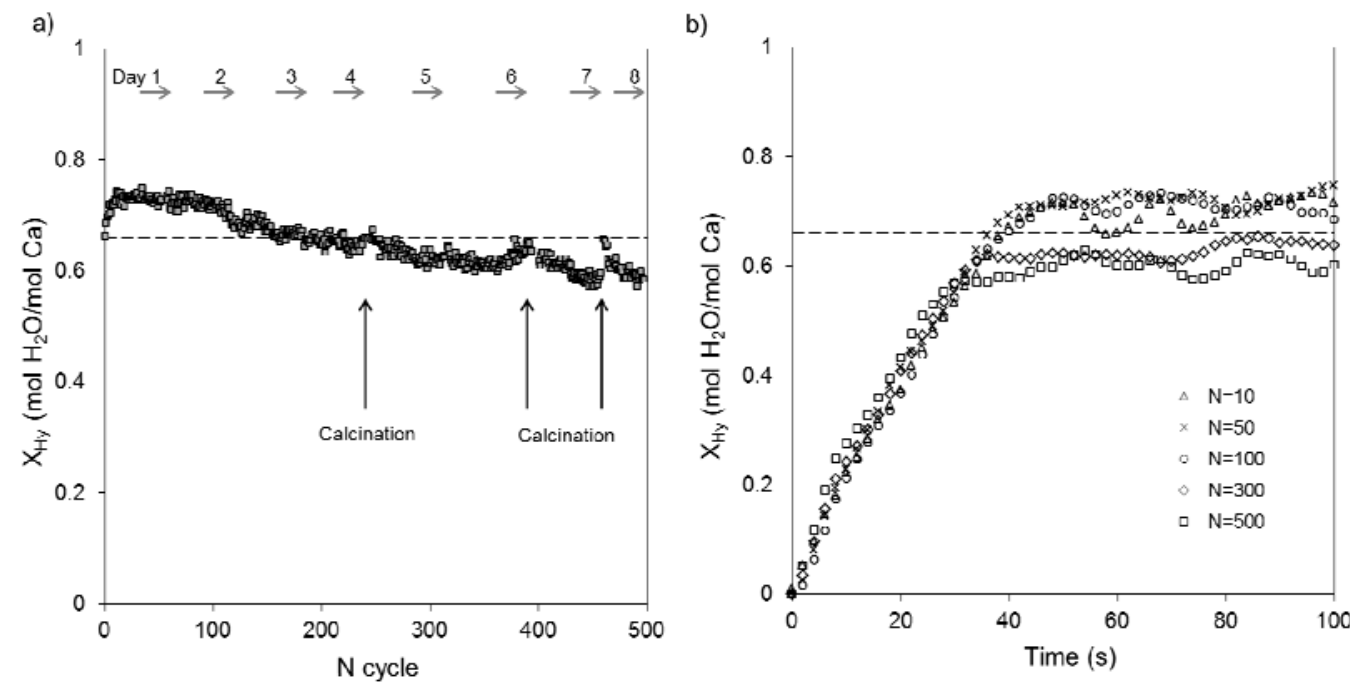

Figure 4. Long duration test ( 8 days) of a material with $\mathrm{r}_{\mathrm{Ca} / \mathrm{S}}=4.8$ subjected to hydration $\left(450^{\circ} \mathrm{C}\right.$ in steam) and dehydration in air. a) Hydration molar conversion $\left(\mathrm{X}_{\mathrm{Hy}}\right)$ after 3 min vs. the number of hydration/dehydration cycles $(\mathrm{N}$ cycle) and $\mathbf{b}) \mathrm{X}_{\mathrm{Hy}}$ vs. time. Corresponding $\mathrm{f}_{\mathrm{CaO}}$ (from equation 7 ) indicated by the dotted line. 
a)

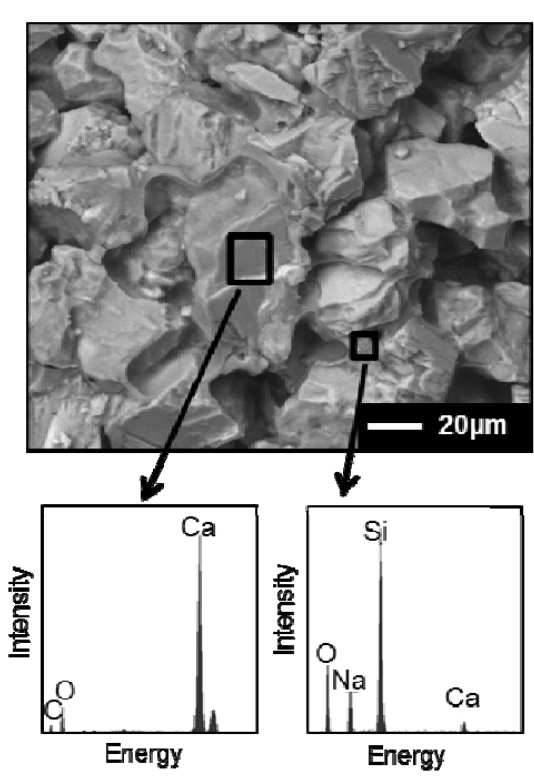

b)

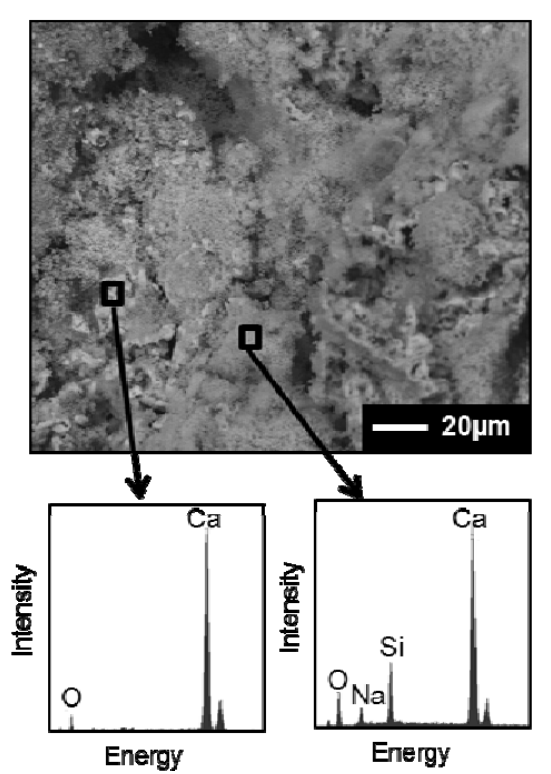

Figure 5. SEM images of a composite material prepared using $\mathrm{CaCO}_{3}$ of $36-63 \mu \mathrm{m}$ and $\mathrm{r}_{\mathrm{Ca} / \mathrm{Si}}=4.8$. a) Fresh composite (after curing) and $\mathbf{b}$ ) material after the cycling test of Figure $4(\mathrm{~N}$ cycle $=500)$. EDAX testing areas indicated by rectangles. 

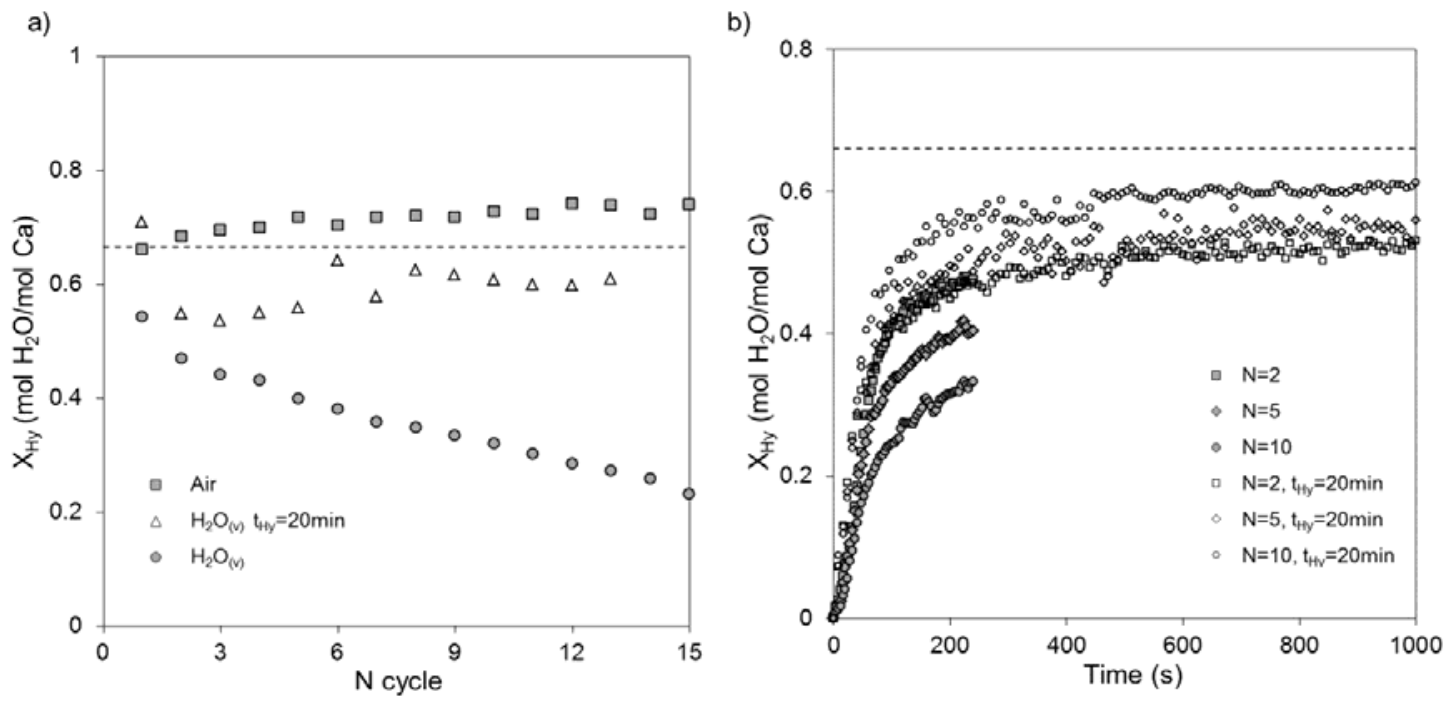

Figure 6. Effect of the dehydration atmosphere on the reactivity of the material. a)

Squares refer to dehydration under air at $500^{\circ} \mathrm{C}$ and circles and triangles to dehydration under pure steam at $550^{\circ} \mathrm{C}$ and $\mathbf{b}$ ) both tests under pure steam at $550^{\circ} \mathrm{C}$. Rest of the conditions as in Figure 4 (except blank points where the hydration time is $20 \mathrm{~min}$ ). 


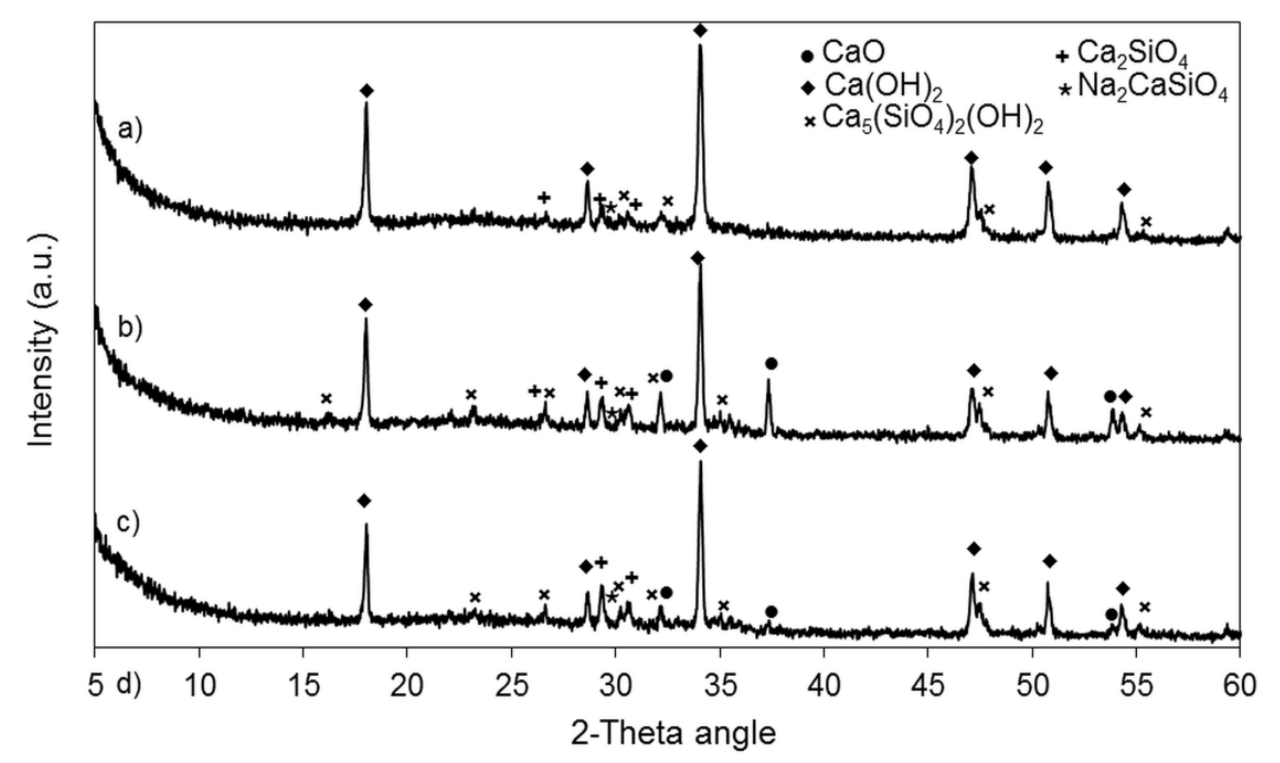

Figure 7. XRD results for different hydrated materials after 20 hydration/dehydration cycles and prepared using 36-63 $\mu \mathrm{m} \mathrm{CaCO}_{3}$ and $\mathrm{r}_{\mathrm{Ca} / \mathrm{Si}}=4.8$. Dehydration at a) $500^{\circ} \mathrm{C}$ under air and b) and c) $550^{\circ} \mathrm{C}$ under pure steam. Sample c) also carbonated at $750^{\circ} \mathrm{C}$ under pure $\mathrm{CO}_{2}$ for 20 min followed by a second calcination before cycling. 


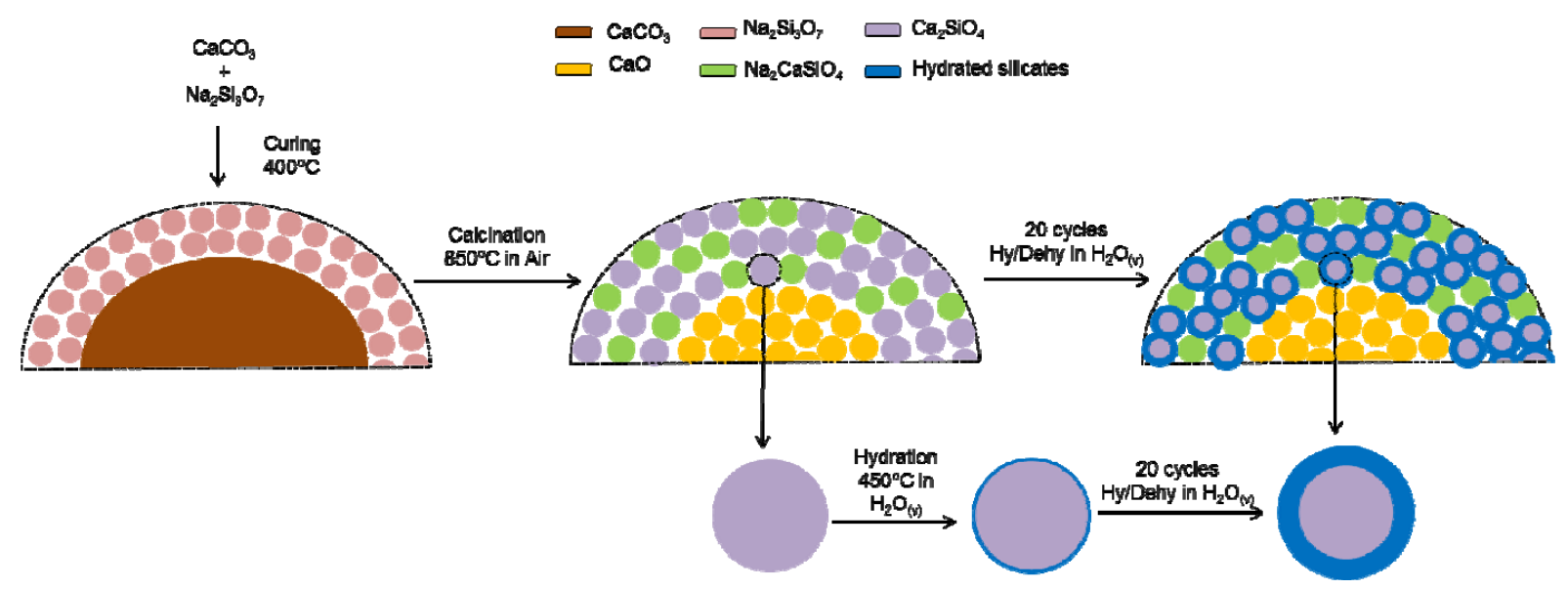

Figure 8. Mechanism proposed for the formation of species observed by XRD during dehydration in pure steam, resulting in a decay in hydration conversion of $\mathrm{CaO}$ due to the growth of hydrated silicates. 

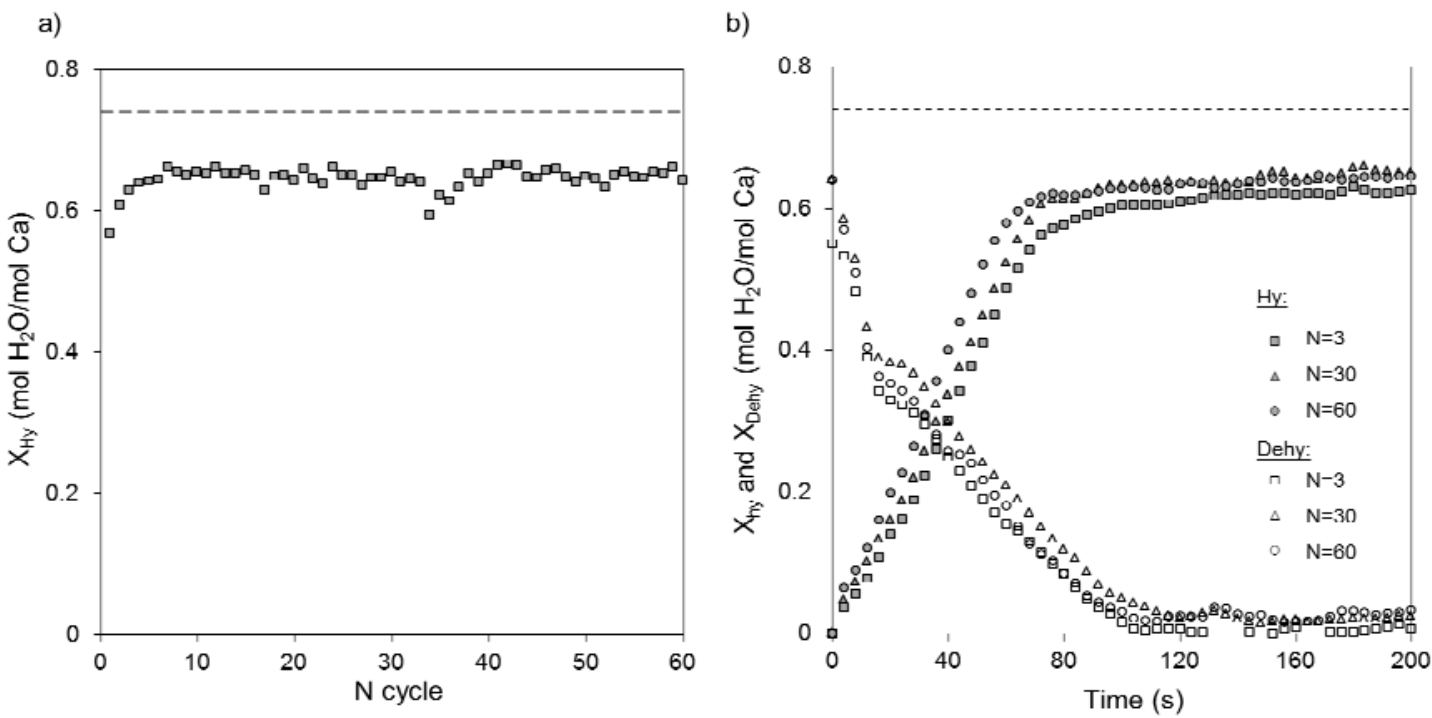

Figure 9. Example of material stability when a carbonation/calcination stage is introduced. a) Hydration conversion $\left(\mathrm{X}_{\mathrm{Hy}}\right)$ vs. the number of hydration/dehydration cycles $(\mathrm{N}$ cycle) and $\mathbf{b})$ hydration and dehydration conversions ( $\mathrm{X}_{\mathrm{Hy}}$ and $\left.\mathrm{X}_{\text {Dehy }}\right)$ vs. time. Dehydration at $550^{\circ} \mathrm{C}$ in pure steam. Composite material with a $\mathrm{r}_{\mathrm{Ca} / \mathrm{Si}}=6.2\left(\mathrm{f}_{\mathrm{CaO}}=0.74\right.$ indicated by dotted line). Carbonation carried out under $\mathrm{CO}_{2}$ at $750^{\circ} \mathrm{C}$ for $20 \mathrm{~min}$ and calcinations under air at $850^{\circ} \mathrm{C}$ for $10 \mathrm{~min}$. 


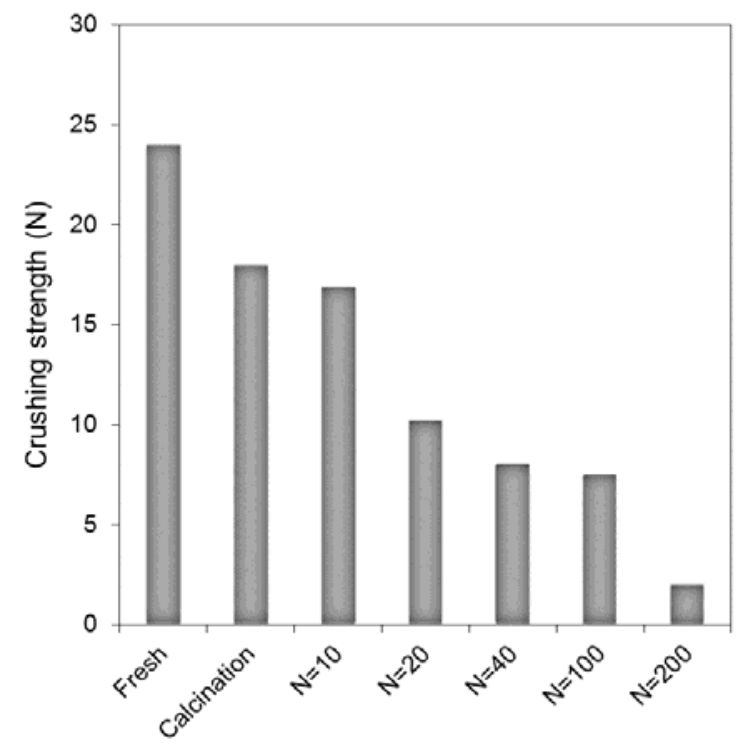

Figure 10. Crushing strength in $\mathrm{N}$ for a fresh, calcined and after different number of hydration/dehydration cycles material as the one represented in Figure 9. 


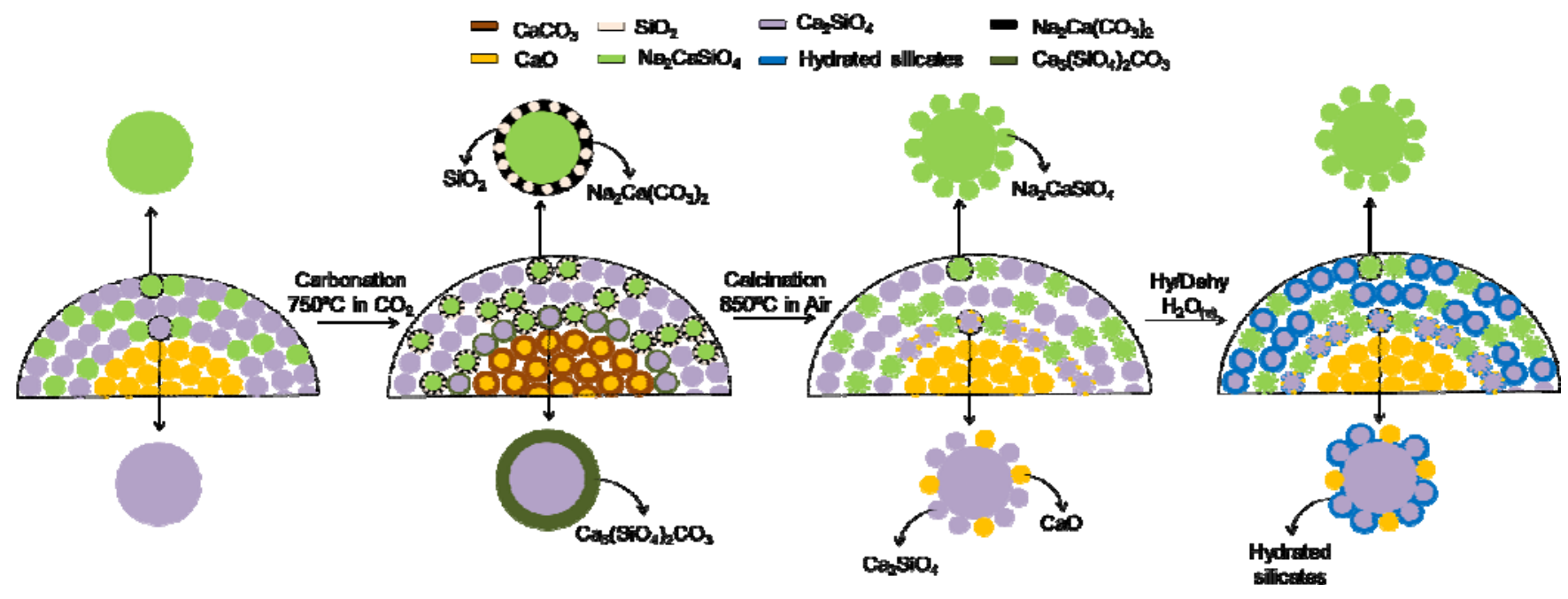

Figure 11. Mechanism proposed for the formation of species observed by XRD after an additional carbonation/calcination step and subsequent hydration/dehydration cycles under pure steam. 
Table 1. Crushing strength (CS) of composite materials and maximum chemical activity values (hydration under pure steam at $450^{\circ} \mathrm{C}$ after $200 \mathrm{~s}$ of reaction)

\begin{tabular}{|c|c|c|c|c|c|c|}
\hline \multicolumn{7}{|c|}{$\begin{array}{l}\text { Effect of Ca- Precursor } \\
\text { Precursor particle size }<36 \mu \mathrm{m}\end{array}$} \\
\hline $\begin{array}{l}\text { Ca- } \\
\text { precursor }\end{array}$ & $\mathbf{r}_{\mathrm{Ca} / \mathrm{Si}}$ & \multicolumn{2}{|c|}{ Fresh CS (N) } & $\begin{array}{c}\mathrm{X}_{\mathrm{Hy}}(\mathrm{mol} \\
\left.\mathrm{H}_{2} \mathrm{O} / \mathrm{mol} \mathrm{Ca}\right)\end{array}$ & $\begin{array}{c}\text { Weight fraction } \\
\mathrm{H}_{2} \mathrm{O} / \text { calcined } \\
\text { sample }\end{array}$ & $\begin{array}{c}\mathrm{H}_{2} \mathrm{O} \\
\text { absorption } \\
\text { capacity (\%) }\end{array}$ \\
\hline \multirow{2}{*}{$\mathrm{CaCO}_{3}$} & 6.2 & \multicolumn{2}{|c|}{26.0} & 0.80 & 0.196 & 61.1 \\
\hline & 2.0 & \multicolumn{2}{|c|}{$>30$} & 0.34 & 0.074 & 23.1 \\
\hline $\mathrm{CaO}$ & 2.3 & \multicolumn{2}{|c|}{5.9} & 0.30 & 0.081 & 25.4 \\
\hline $\mathrm{Ca}(\mathrm{OH})_{2}$ & 2.0 & \multicolumn{2}{|c|}{4.2} & 0.33 & 0.073 & 23.0 \\
\hline \multicolumn{7}{|c|}{$\begin{array}{c}\text { Calcination conditions } \\
\text { cursor } \mathrm{CaCO}_{3} 36-63 \mu \mathrm{m}, \mathrm{r}_{\mathrm{Ca} / \mathrm{S}}=4.8\left(\mathrm{f}_{\mathrm{CaO}}\right.\end{array}$} \\
\hline \multicolumn{2}{|c|}{ Temperature, time } & $\begin{array}{l}\text { Fresh } \\
\text { CS (N) }\end{array}$ & $\begin{array}{l}\text { Calcined } \\
\text { CS (N) }\end{array}$ & $\begin{array}{c}\mathrm{X}_{\mathrm{Hy}}(\mathrm{mol} \\
\left.\mathrm{H}_{2} \mathrm{O} / \mathrm{mol} \mathrm{Ca}\right)\end{array}$ & $\begin{array}{l}\text { Weight fraction } \\
\mathrm{H}_{2} \mathrm{O} / \text { calcined } \\
\text { sample }\end{array}$ & $\begin{array}{c}\mathrm{H}_{2} \mathrm{O} \\
\text { absorption } \\
\text { capacity (\%) }\end{array}$ \\
\hline \multicolumn{2}{|c|}{$850^{\circ} \mathrm{C}, 10 \mathrm{~min}$} & 28.1 & 17.0 & 0.68 & 0.168 & 52.3 \\
\hline \multicolumn{2}{|c|}{$850^{\circ} \mathrm{C}, 16 \mathrm{~h}$} & 28.1 & 17.8 & 0.68 & 0.168 & 52.3 \\
\hline \multicolumn{2}{|c|}{$650^{\circ} \mathrm{C}, 16 \mathrm{~h}$} & 28.1 & 7.5 & 0.83 & 0.195 & 60.7 \\
\hline \multicolumn{7}{|c|}{$\begin{array}{c}\text { Precursor particle size } \\
\text { Precursor } \mathrm{CaCO}_{3}, \mathrm{r}_{\mathrm{Ca} / \mathrm{Si}}=4.8\left(\mathrm{f}_{\mathrm{CaO}}=0.67\right) \text { except for } 200-400 \mu \mathrm{m} \mathrm{r}_{\mathrm{Ca} / \mathrm{S}}=3.2\left(\mathrm{f}_{\mathrm{CaO}}=0.50\right)\end{array}$} \\
\hline \multicolumn{2}{|c|}{$d_{p}(\mu m)$} & $\begin{array}{l}\text { Fresh } \\
\text { CS (N) }\end{array}$ & $\begin{array}{c}\text { Calcined } \\
\text { CS (N) }\end{array}$ & $\begin{array}{c}\mathrm{X}_{\mathrm{Hy}}(\mathrm{mol} \\
\left.\mathrm{H}_{2} \mathrm{O} / \mathbf{m o l ~ C a}\right)\end{array}$ & $\begin{array}{l}\text { Weight fraction } \\
\mathrm{H}_{2} \mathrm{O} / \text { calcined } \\
\text { sample }\end{array}$ & $\begin{array}{c}\mathrm{H}_{2} \mathrm{O} \\
\text { absorption } \\
\text { capacity (\%) }\end{array}$ \\
\hline \multicolumn{2}{|c|}{ Co-precipitated $\left(\mathrm{d}_{50}=14\right)$} & 9.8 & 5.7 & 0.68 & 0.168 & 52.3 \\
\hline \multicolumn{2}{|c|}{$<36$} & 12.2 & 10.2 & 0.63 & 0.156 & 48.6 \\
\hline \multicolumn{2}{|c|}{$36-63$} & 28.1 & 17.0 & 0.68 & 0.168 & 52.3 \\
\hline \multicolumn{2}{|c|}{$63-100$} & 8.2 & 6.3 & 0.68 & 0.168 & 52.3 \\
\hline \multicolumn{2}{|c|}{$200-400$} & 6.0 & 4.9 & 0.83 & 0.170 & 53.0 \\
\hline \multicolumn{7}{|c|}{$\begin{array}{l}\text { Molar Ca/Si ratio }\left(\mathbf{r}_{\mathrm{Ca} / \mathrm{Si}}\right) \\
\text { Precursor } \mathrm{CaCO}_{3} 36-63 \mu \mathrm{m}\end{array}$} \\
\hline $\mathbf{r}_{\mathrm{Ca} / \mathrm{Si}}$ & $\mathbf{f}_{\mathrm{CaO}}$ & $\begin{array}{l}\text { Fresh } \\
\text { CS (N) }\end{array}$ & $\begin{array}{l}\text { Calcined } \\
\text { CS (N) }\end{array}$ & $\begin{array}{c}\mathrm{X}_{\mathrm{Hy}}(\mathrm{mol} \\
\left.\mathrm{H}_{2} \mathrm{O} / \mathrm{mol} \mathrm{Ca}\right)\end{array}$ & $\begin{array}{c}\text { Weight fraction } \\
\mathrm{H}_{2} \mathrm{O} / \text { calcined } \\
\text { sample }\end{array}$ & $\begin{array}{c}\mathrm{H}_{2} \mathrm{O} \\
\text { absorption } \\
\text { capacity (\%) }\end{array}$ \\
\hline 13.2 & 0.88 & 4.5 & 1.9 & 0.85 & 0.219 & 68.2 \\
\hline 6.2 & 0.74 & 26.0 & 16.2 & 0.75 & 0.190 & 59.1 \\
\hline 4.8 & 0.67 & 28.1 & 17.0 & 0.68 & 0.168 & 52.3 \\
\hline 1.8 & 0.12 & $>30$ & 17.5 & 0.37 & 0.071 & 22.1 \\
\hline
\end{tabular}




\section{Figure captions:}

Figure 1. XRD results for a composite material prepared using $\mathrm{CaCO}_{3}$ of $36-63 \mu \mathrm{m}$ and a $\mathrm{r}_{\mathrm{Ca} / \mathrm{Si}}=4.8$. a) Fresh particle (after curing), b) after calcination at $850^{\circ} \mathrm{C}$ for $10 \mathrm{~min}$ and c) after calcination at $650^{\circ} \mathrm{C}$ for $16 \mathrm{~h}$.

Figure 2. XRD results for a composite material prepared using co-precipitated $\mathrm{CaCO}_{3}$ $\left(\mathrm{d}_{50}=14 \mu \mathrm{m}\right)$ and $\mathrm{r}_{\mathrm{Ca} / \mathrm{Si}}=1.5$. After a) calcination at $850^{\circ} \mathrm{C}$ in an oven for $\left.1 \mathrm{~h}, \mathbf{b}\right)$ calcination at $850^{\circ} \mathrm{C}$ followed by carbonation in pure $\mathrm{CO}_{2}$ at $750^{\circ} \mathrm{C}$ and c) calcination at $850^{\circ} \mathrm{C}$ followed by carbonation in pure $\mathrm{CO}_{2}$ at $650^{\circ} \mathrm{C}$.

Figure 3. Hydration conversion $\left(\mathrm{X}_{\mathrm{Hy}}\right)$ as a function of time for a) five different particle sizes: co-precipitated $\mathrm{CaCO}_{3}\left(\mathrm{~d}_{50}=14 \mu \mathrm{m}\right)$ and Imeco $\mathrm{CaCO}_{3}<36,36-63,63-100$ and 200-400 $\mu \mathrm{m}, \mathrm{r}_{\mathrm{Ca} / \mathrm{Si}}=4.8$ (except for $\mathrm{d}_{\mathrm{p}}=200-400 \mu \mathrm{m}, \mathrm{r}_{\mathrm{Ca} / \mathrm{Si}}=3.2$ ) and $\mathbf{b}$ ) for four different $\mathrm{r}_{\mathrm{Ca} / \mathrm{Si}}$ : 13.2, 6.2, 4.8 and 1.8 using $\mathrm{Imeco} \mathrm{CaCO}_{3}$ of $36-63 \mu \mathrm{m}$ as Ca-precursor. Corresponding $\mathrm{f}_{\mathrm{CaO}}$ (from equation 7 ) indicated by the dotted lines.

Figure 4. Long duration test ( 8 days) of a material with $\mathrm{r}_{\mathrm{Ca} / \mathrm{S}}=4.8$ subjected to hydration $\left(450^{\circ} \mathrm{C}\right.$ in steam) and dehydration in air. a) Hydration molar conversion $\left(\mathrm{X}_{\mathrm{Hy}}\right)$ after 3 min vs. the number of hydration/dehydration cycles ( $\mathrm{N}$ cycle) and $\mathbf{b}) \mathrm{X}_{\mathrm{Hy}}$ vs. time. Corresponding $\mathrm{f}_{\mathrm{CaO}}$ (from equation 7 ) indicated by the dotted line.

Figure 5. SEM images of a composite material prepared using $\mathrm{CaCO}_{3}$ of $36-63 \mu \mathrm{m}$ and $\mathrm{r}_{\mathrm{Ca} / \mathrm{Si}}=4.8$. a) Fresh composite (after curing) and b) material after the cycling test of Figure $4(\mathrm{~N}$ cycle $=500)$. EDAX testing areas indicated by rectangles.

Figure 6. Effect of the dehydration atmosphere on the reactivity of the material. a) Squares refer to dehydration under air at $500^{\circ} \mathrm{C}$ and circles and triangles to dehydration under pure steam at $550^{\circ} \mathrm{C}$ and $\left.\mathbf{b}\right)$ both tests under pure steam at $550^{\circ} \mathrm{C}$. Rest of the conditions as in Figure 4 (except blank points where the hydration time is $20 \mathrm{~min}$ ). 
Figure 7. XRD results for different hydrated materials after 20 hydration/dehydration cycles and prepared using 36-63 $\mu \mathrm{m} \mathrm{CaCO}_{3}$ and $\mathrm{r}_{\mathrm{Ca} / \mathrm{Si}}=4.8$. Dehydration at a) $500^{\circ} \mathrm{C}$ under air and b) and c) $550^{\circ} \mathrm{C}$ under pure steam. Sample c) also carbonated at $750^{\circ} \mathrm{C}$ under pure $\mathrm{CO}_{2}$ for 20 min followed by a second calcination before cycling.

Figure 8. Mechanism proposed for the formation of species observed by XRD during dehydration in pure steam, resulting in a decay in hydration conversion of $\mathrm{CaO}$ due to the growth of hydrated silicates.

Figure 9. Example of material stability when a carbonation/calcination stage is introduced. a) Hydration conversion $\left(\mathrm{X}_{\mathrm{Hy}}\right)$ vs. the number of hydration/dehydration cycles $(\mathrm{N}$ cycle) and $\mathbf{b})$ hydration and dehydration conversions $\left(\mathrm{X}_{\mathrm{Hy}}\right.$ and $\left.\mathrm{X}_{\text {Dehy }}\right)$ vs. time. Dehydration at $550^{\circ} \mathrm{C}$ in pure steam. Composite material with a $\mathrm{r}_{\mathrm{Ca} / \mathrm{Si}}=6.2\left(\mathrm{f}_{\mathrm{CaO}}=0.74\right.$ indicated by dotted line). Carbonation carried out under $\mathrm{CO}_{2}$ at $750^{\circ} \mathrm{C}$ for $20 \mathrm{~min}$ and calcinations under air at $850^{\circ} \mathrm{C}$ for $10 \mathrm{~min}$.

Figure 10. Crushing strength in $\mathrm{N}$ for a fresh, calcined and after different number of hydration/dehydration cycles material as the one represented in Figure 9.

Figure 11. Mechanism proposed for the formation of species observed by XRD after an additional carbonation/calcination step and subsequent hydration/dehydration cycles under pure steam. 
For Table of Contents Only

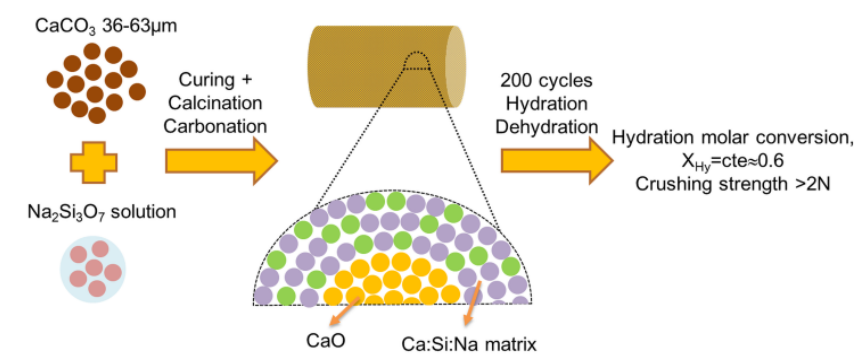

